\title{
o3. Latin harfli çeviri yazı metinlerinde konuşma dilini yansıtan yazım şekli özellikleri (16. - 18. yy.) ${ }^{1}$
}

\section{Suat ÖZER²}

\begin{abstract}
APA: Özer, S. (2021). Latin harfli çeviri yazı metinlerinde konuşma dilini yansıtan yazım şekli özellikleri (16. - 18. yy.) RumeliDE Dil ve Edebiyat Araştırmalar Dergisi, (22), 42-66. DOI: 10.29000/rumelide.885439.
\end{abstract}

\section{$\ddot{\mathbf{O} z}$}

Türkçe, tarihin eski zamanlarından bu yana çeşitli alfabelerle yazıya geçirilmiştir. Bu alfabeler arasında bulunan Latin alfabesi, Osmanlı Devletinin yükselme dönemine denk gelecek biçimde Avrupalılar tarafından Türkçe için de kullanılmıştır. Türkçenin Latin harfleriyle yazıldığı bu türden tarihî metinlere çeviri yazı (transkripsiyon) metinleri, çeviri yazılı metinler veya aracı (mediator) metinler adı verilir. Çeviri yazı metinleri kaleme alan yazarlar, öncelikle kendi dildaşlarına dışardaki dünyayı anlatmak, o dünyaya ait kelimeleri tanıtmak, giderek o dili öğretmek amacını pratik bir yolla gerçekleştirmek istemişlerdir. Bu yeni dil ve kültür çevresini tanımlamada araç olarak âşinâ oldukları Latin harflerini kullanmışlardır. Standartların henüz oluşmadığı bir dönemde her bir yazarın kendi ses bibliyografyasına göre notasyon yapması beklenir bir öngörüdür. $\mathrm{Bu}$ notasyonda konuşmacının amacı, vurgusu, iletişimin kalitesi, bağlam vb. unsurlara bağlı olarak çok şekilli ve çok katmanlı bir yapının üretileceği de varsayılabilir. Benzer şekilde yazarların kendi dillerindeki sınırlı harf koleksiyonunu Türkçeye ait sesler için kullanmasının yazım yanında sesletim olanakları hakkında da bilgi vermesi beklenebilir. Yazıma ait dış özellikler arasında sayılabilecek bitişik veya ayrı yazımlar, döneme ait konuşmanın izlerini taşıyabilir. Ayrıca aynı eserde aynı kavrama işaret eden aynı sözcüklerin birden fazla şekilde yazılması yanında yanlış yazıldığı varsayılan sözcükler bile konuşma diline ait bir özelliğin varlığına işaret edebilir. Bu makale, bu türden varsayımların çeviri yazı metinleri bağlamında ne derece geçerli olduğunu tartışmak amacıyla kaleme alınmıştır. Çalışmamızda Türkçenin 16. ve 18. yüzyılları arasına ait 12 çeviri yazı metninden oluşan bir bütünceye dayalı olarak anılan yazım özelliklerine göre sesletim hususiyetleri incelenmiştir.

Anahtar kelimeler: Türkçe, Osmanlı Türkçesi, çeviri yazı metinleri, yazım, konuşma dili.

\section{Properties of writing form reflecting the spoken language in Latin-letter transcription texts $\left(16^{\text {th }}-18^{\text {th }}\right.$ cent.)}

\begin{abstract}
Turkish has been written in various alphabets since old times. Among these alphabets, the Latin alphabet was used for Turkish by Europeans, at the same time as the rise of the Ottoman Empire. Such historical texts in which Turkish is written in Latin letters are called transcription texts or mediator texts. The authors who wrote transcription texts first wanted to explain the world outside to their speakers of the same language, to introduce the words of that world, and to gradually teach
\end{abstract}

Bu çalışma "Latin harfli çeviri yazı metinlerinde konuşma dili olarak Türkçe (16. - 18. yy.)" başlıklı doktora tezi temel alınarak düzenlenmiştir.

Doktora Öğrencisi., Çukurova Üniversitesi, Sosyal Bilimler Enstitüsü, Türk Dili ve Edebiyatı Bölümü (Adana, Türkiye), suattauso1@yahoo.com, ORCID ID: 000o-0001-9046-6856 [Araştırma makalesi, Makale kayıt tarihi: 07.01.2020-kabul tarihi: 20.03.2021; DOI: 10.29000/rumelide.885439.]

\section{Adres $\mid$ Address}

RumeliDE Dil ve Edebiyat Araşttrmaları Dergisi Osmanağa Mahallesi, Mürver Ciçeği Sokak, No:14/8 Kadıköy - İSTANBUL / TÜRKIYE 34714 e-posta: editor@rumelide.com

RumeliDE Journal of Language and Literature Studies

Osmanağa Mahallesi, Mürver Çiçeği Sokak, No:14/8

Kadıköy - ISTANBUL / TURKEY 34714

e-mail: editor@rumelide.com,

tel: +90 505 7958124, +90 2167730616 phone: +90 505 7958124, +90 2167730616 
that language in a practical way. They used familiar Latin letters as a tool to describe this new language and cultural environment. In a period when standards are not yet established, it is expected that each author will notation according to their own voice bibliography. In this notation, the speaker's purpose, emphasis, quality of communication, context, etc. it can also be assumed that a multi-shaped and multi-layered structure will be produced depending on the elements. Similarly, the authors' use of the limited letter collection for Turkish sounds can be expected to give information about the possibilities of pronunciation as well as spelling. Contiguous or separate spellings that can be considered among the external features of spelling may bear the traces of the speech of the period. In addition, writing the words pointing to the same concept in more than one way in the same work, even the words that are assumed to be misspelled may indicate the presence of a feature of the spoken language. This article is written to discuss the extent to which such assumptions are valid in the context of transcription text. In our study, the phonetic characteristics of Turkish were examined based on the aforementioned spelling features based on a corpus consisting of 12 transcription texts belonging to the 16th and 18th centuries.

Keywords: Turkish, Ottoman Turkish, transcription texts, orthography, spoken language

\section{Giriş}

Avrupalıların 15.yy.dan itibaren Türkçeye gösterdikleri ilginin neticesinde ortaya çıkan pratik amaçla dil öğrenme ihtiyacı, çeviri yazı metinlerinin (bundan sonra ÇYM) yayımlanmasına neden olmuştur. $\mathrm{Bu}$ metinlerde Türkçe sesletimi göstermek için kullanılan Latin harflerinin güvenilirliği yazarların becerisi, bilgisi, amacı ve doğruluğuna göre değiştiğinden tam bir standartlaşmadan söz edilemez ve eserleri bu bakımdan derecelendirmek gerekir. Ancak ilgili metinlerin Arap alfabesinin sınırlamaları veya Osmanlı ortografyasının muhafazakârlığı tarafından gizlenen bazı fonolojik olguların açığa çıkarılmasında kayda değer bir işlev üstlendikleri söylenebilir.

Türkoloji literatüründe çeviri yazı metinlerinin önemi, tarihî dilsel çalışmalarda karşılaşılan fonetik / seslik problemlerin (özellikle dudak uyumu) çözümlenmesinde sağladıkları yarardan kaynaklanır (Dilaçar 1970, s. 201 - 204; Adamović 1974; Tulum, 2007, s. 347; Duman, 1995, s. 7 / 2013, s. 175; Develi 1998, s. 29; Gümüşkilıç 2005; Kartallığlu, 2011; Yağmur, 2014, s. 204 - 206). Hazai (2012) bu durumu, Arap yazılı kaynakların sustuğu noktada transkripsiyon anıtlarının konuşmaya başladığı (s. 37) şeklinde değerlendirir. İlgili eserlere eleştirel yaklaşan çalışmalar da bulunur. Eleştirilerin bir bölümü eserlerin Türk kaynaklı olmaması (Kissling 1968) bir bölümü de Deny'de (1941) ifadesini bulan “(...) Fransız ve Latin gramerlerinde güdülen dili sergileyiş itiyat ve tarzlarını Türkçenin tahsil ve talimi hususunda da muhafaza etmek gibi bir nakısa ile malûldürler.” (s. I) şeklindeki Türk dilinin morfolojik sisteminin Hint - Avrupa dillerinden ayrı yapılmasının gereğine yapılan vurgu kaynaklıdır. Hazai (2012) tarihî morfolojik çalışmalar açısından benzer bir tespiti, Arap harfli metinler esas, çeviri yazı metinleri ise ancak ikincil bir rol oynayabilir (s. 55) şeklinde devam ettirmektedir. Çeviri yazı metinleri açısından bu durumun gramatikal formlar ve yazı ile ilgili hususlarda göz önünde bulundurulması gereken önemli bir nokta olduğunu hatırlatmakta fayda bulunmaktadır.

Bilindiği üzere Latin harfleri alfabetik bir özellik taşır. Alfabede kullanılan her karakterin bir sese göre kodlandığı bu sistemde seçilen alfabe seti, seslerin ayrıntılarını gizleyicidir ve bu yüzden "genelleme" prensibini gözetir. ÇYM'lerde ise duyulanı yazıya geçirirken neredeyse yeni bir dil kuran yazarlar için "Sesi esas aldıkları için genelleme prensibinin tersine hareket etmiştir." denilebilir. Harflerin üzerindeki özel işaretlerin gittikçe artması ( $c, \bar{a}^{`}$ vb.), diyakritikler ( $\check{c}, \check{s}$ vb.), ayırıcı imler $\left(k^{i}, g^{i}, s^{i}, c^{i}\right.$

\footnotetext{
Adres
RumeliDE Dil ve Edebiyat Araştırmaları Dergisi Osmanağa Mahallesi, Mürver Ciçeği Sokak, No:14/8 Kadıköy - İSTANBUL / TÜRKIYE 34714 e-posta: editor@rumelide.com tel: +90 505 7958124, +90 2167730616 


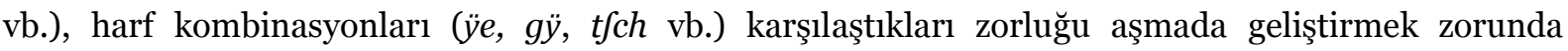
kaldıkları bir yöntem olmalıdır. Yazarlar arasında dil öğretimini veya tercümanlığı meslek edinenler harf setlerini kendi bilgileri oranında daha da arttırmışlardır. İşin başında (16. yy.) daha sade bir harf /ses sistemi daha çok amatörler (seyyah, tacir, hevesliler vb.) tarafından üretilirken doğrudan dille uğraşanların (tercüman, elçilik, dini görevliler vb.) ürettiği metinlerdeki ayrıntılı gelişme ve genişleme (18. yy.) bu eserlerin karakteristik bir özelliği haline gelmiştir. Yukarıda andığımız genişleme ilkesi standartlaşma, merkezileşme, genelleme ve gizleme gibi yazı dilini çağrıştıran kavramların aksine bir gelişmedir. ÇYM’ler bu bakımdan başlı başına konuşma dili lehine üretimler sayılabilir.

Genel olarak yazı için kullanılan semboller, konuşmayı aktarmak için kullanılabileceği gibi bir yazı sisteminden diğerine aktarma için de kullanılabilir. Bu bağlamda ÇYM’ler olarak adlandırılan eserler, ortografik transkripsiyon ${ }^{3}$ başlığı altında ele alınabilir ve fonetik yanında karakter eşlemelerini de içerdiği eklenebilir. ÇYM’lerde Türkçenin Latin harflerine aktarılmış bir formu olduğu görülmektedir. Bazı eserlerde Arap harfleri ile Latin harflerinin eşleniklik tablosu da hazırdır (ILT 1612; RGT 1630; SL 1643; PGT 1794) ve sistemli olarak eşlenmiş diğer metin oluşturulur. Bazı eserlerde ise doğrudan Latin harfleri ile yazıya geçirilmiş (ON 1527; TRC 1544; HPT 1575; TG 1581; DDLT 1641; CFT 1672; BGD 1781; GT 1789 ) bu yüzden de grafik eşleme olmadan nispeten fonetiğe dayalı daha serbest formların kullanıldığı (çok şekilli yazımlar bazen tutarsızlıklar doğursa da) görülür. Her iki yazı sistemi de konuşma dilinin yazıya geçirilmesi uygulamasına bağlı kalarak ortografik sınırlarda kalır. İlkinde hece, gramer etkisi diğerinde sözlü dilin etkisi önde görünmektedir.

Yukarıda andığımız çerçeve ilkeler dâhilinde ÇYM’lerin yazım şekline ait özellikleri incelenmiştir. Öncelikle eserlerde kullanılan harflerin seslik değerleri bir tabloda gösterilmiştir. Ardından bitişik yazıma bağlı sesletim özellikleri başlı̆̆ı altında bitişik yazılan niteleyici sözcük ve yapılar, edat ve bağlaçlar, ek fiil ve yardımcı fiiller, soru eki ve anlamca kaynaşmış yapılar ele alınmış devamında ayrı yazılmış örnekler sesletim bakımından incelenmiştir. Aynı eserde aynı kavrama işaret etmek üzere farklı yazılmış örnekler biçimsel seslik özellikler ve nöbetleşme alt başlığı ile incelenmiş ve yanlış yazımdan kaynaklı örnekler de sesletim açısından ele alınmışlardır. Böylece anılan dönemdeki Türkçenin sesletim özellikleri, ilgili eserlerden elde edilen yazım şekline dair veriler bağlamında betimlenmeye çalışılmıştır.

\section{Eserlerin dili ve ses değerleri}

İncelediğimiz metinlerde açıklama bölümleri Latince, İtalyanca ve Fransızca ile yapılmıştır. Latin harfleri kullanılan metinlerin dilsel dağılımında Latince olanlar arasında TRC / 1544 - Georgiyevitz, TG / 1581 - Crisisus (Grekçe ve Latince), ILT / 1612 - Megiser, SL / 1643 - Maggio, CFT / 1672 Harsany; İtalyanca olanlar arasında ON / 1527 -Valentiano, DDLT / 1641 - Molino, BGD / 1781 Pianzola (Latince ve İtalyanca), PGT / 1794 - Carbognano; Fransizca ve Latince birlikte olanlar HPT / 1575 - Postel, RGT / 1630 - Du Ryer, GT / 1789 - Preindl bulunmaktadır.

Türkçenin seslerini tarifte Latin harfleri ortak kullanılsa da yeni bir dilin ses aralıklarını tarif ederken yazarın kendi anadiline ve ses malzemesine yaslanması gayet doğaldır. Rocchi, L. (2015), bu durumu Preindl özelinde "Türkçe kelimeleri yazmak için sadece Latin alfabesini kullanır (Bu nedenle metni

Heselwood, B. (2013) fonetik transkripsiyonu ele aldığı çalışmasında yazıyı gösteren notasyonun imlâ için karakterlerin (Sözcük ve gramere ait değerleri göstermede kullanılır.) transkripsiyon içinse sembollerin (Sesletimin analizini göstermek için kullanılır.) kullanılarak gerçekleştirildiğini şematize etmiştir (s. 10, şekil 1.2). İlgili ayrıma göre birincide alfabetik hece sisteminin diğerinde ise telaffuzun esas alındığı söylenebilir. ÇYM’ler bağlamında 16. yy.a ait başlangıç eserlerinde sesletimin 18. yy. eserlerinde standartlaşmaya bağlı olarak yazı dilinin öncelikleri etkili olmuştur denilebilir.

\section{Adres $\mid$ Address}

RumeliDE Dil ve Edebiyat Araşttrmaları Dergisi $\quad$ RumeliDE Journal of Language and Literature Studies Osmanağa Mahallesi, Mürver Çiçeği Sokak, No:14/8 Osmanağa Mahallesi, Mürver Çiçeği Sokak, No:14/8

Kadıköy - ISTANBUL / TÜRKIYE 34714 Kadıköy - ISTANBUL / TURKEY 34714 e-posta: editor@rumelide.com

e-mail: editor@rumelide.com

tel: +90 505 7958124, +90 2167730616 phone: +90 505 7958124, +90 2167730616 
klasik bir transkripsiyon metnidir.) ancak Fransızca ve Almanca yazım kurallarını karıştırır.” (s. 266) şeklindeki tespit etmektedir. Bu bakımdan çeviri yazı metinlerinde referans noktası olan Latin harflerinin Türkçe ses değerleri ile denkleştirilmesi gereklidir. Bu halde karşlaştırma yapabilmek ve harf / ses aralıklarını daha sarîh gösterebilmek bakımından eşleşmeler Tablo 1'de gösterilmiştir.

Tablo 1: Çeviri yazı metinlerinde kullanılan Latin alfabesi tablosu

\begin{tabular}{|c|c|c|}
\hline Yazım & Ses & IPA Karakteri \\
\hline $\mathrm{a}$ & $\mathrm{a}$ & [a] \\
\hline$æ$ & $\ddot{a}$ & [æ] \\
\hline $\mathrm{b}$ & $\mathrm{b}$ & [b] \\
\hline $\mathrm{c} \sim \mathrm{g} \sim \overline{\mathrm{g}} \sim \mathrm{z} \sim \mathrm{gi} \sim \mathrm{g} \int \sim \mathrm{gs} \sim \mathrm{gz} \sim \mathrm{d} \int \mathrm{ch}$ & $\mathrm{c}$ & {$[\mathrm{d} \tilde{3}]$} \\
\hline $\mathrm{c} \sim \mathrm{c} \sim \check{\mathrm{c}} \sim \mathrm{z} \sim \mathrm{cc} \sim \mathrm{ch} \sim \mathrm{c}^{\mathrm{i}} \sim \mathrm{cs} \sim \mathrm{cl} \sim \mathrm{cz} \sim \mathrm{ts} \sim \mathrm{t} \int \sim \mathrm{tz} \sim \mathrm{zh} \sim \mathrm{t} f \mathrm{ch}$ & ç & {$\left[\mathrm{t} \int\right]$} \\
\hline $\mathrm{d} \sim \mathrm{t}$ & $\mathrm{d}$ & [d] \\
\hline $\mathrm{e} \sim \varepsilon$ & $\mathrm{e}$ & {$[\mathrm{e}],[\varepsilon]$} \\
\hline $\mathrm{f} \sim \mathrm{ph}$ & f & {$[\mathrm{f}]$} \\
\hline $\mathrm{g} \sim \mathrm{gc} \sim \mathrm{gh} \sim \mathrm{gi} \sim \mathrm{gi} \sim \mathrm{gk} \sim \mathrm{gy} \sim \mathrm{g} \ddot{\mathrm{y}} \sim \mathrm{ghi}$ & $\mathrm{g}$ & {$[\mathrm{f}]$} \\
\hline gh & $\dot{\mathrm{g}}(\breve{\mathrm{g}})$ & {$[\gamma]$} \\
\hline $\mathrm{h} \sim \mathrm{ch} \sim \mathrm{hh} \sim \mathrm{chh}$ & h (h) & [h] \\
\hline $\mathrm{e} \sim \mathrm{i} \sim \mathrm{y}$ & 1 & [i] \\
\hline $\mathrm{i} \sim \mathrm{j} \sim \mathrm{y}$ & $\mathrm{i}$ & [i] \\
\hline- & $\mathrm{j}$ & [3] \\
\hline $\mathrm{c} \sim \mathrm{c} \sim \mathrm{k} \sim \mathrm{k}^{\mathrm{i}} \sim \mathrm{ch} \sim \mathrm{ck} \sim \mathrm{ki} \sim \mathrm{kk} \sim \mathrm{ckh}$ & $\mathrm{k}$ & [c] \\
\hline $\mathrm{c} \sim \mathrm{ch} \sim \mathrm{q}$ & $\mathrm{k}$ & {$[\mathrm{k}]$} \\
\hline 1 & 1 & [1], [ł] \\
\hline $\mathrm{m} \sim \mathrm{mm}$ & $\mathrm{m}$ & {$[\mathrm{m}]$} \\
\hline $\mathrm{n}$ & $\mathrm{n}$ & {$[\mathrm{n}]$} \\
\hline $\mathrm{ng} \sim \mathrm{ngh}$ & $\mathrm{y}$ & {$[\mathrm{n}]$} \\
\hline ny & $\mathrm{n}$ & {$[\mathrm{n}]$} \\
\hline o & o & {$[0],[0]$} \\
\hline io $\sim \ddot{0}$ & $\ddot{0}$ & [œ] \\
\hline $\mathrm{p}$ & $\mathrm{p}$ & [p] \\
\hline $\mathrm{r}$ & $\mathrm{r}$ & {$[\mathrm{r}]$} \\
\hline $\mathrm{s} \sim \int \sim \beta \sim \mathrm{t} \int \sim \mathrm{ts}$ & s & {$[\mathrm{s}]$} \\
\hline$\check{\mathrm{s}} \sim \mathrm{s} \sim \mathrm{s} \sim \mathrm{s}^{\mathrm{i}} \sim \int \sim \mathrm{ch}-\mathrm{fc} \sim \mathrm{sc} \sim \mathrm{ss} \sim \iint \sim \mathrm{sZ} \sim \int \mathrm{ch}$ & Ş & {$\left[\int\right]$} \\
\hline $\mathrm{t} \sim \mathrm{th}$ & $\mathrm{t}$ & {$[\mathrm{t}]$} \\
\hline $\mathrm{u}$ & $\mathrm{u}$ & {$[\mathrm{u}],[\mathrm{\sigma}]$} \\
\hline $\mathrm{iu} \sim \ddot{\mathrm{u}}$ & $\ddot{\mathrm{u}}$ & [y] \\
\hline $\mathrm{u} \sim \mathrm{v}$ & $\mathrm{v}$ & {$[\mathrm{v}]$} \\
\hline $\mathrm{j} \sim \mathrm{i} \sim \mathrm{y}$ & $\mathrm{y}$ & [j] \\
\hline $\mathrm{S} \sim \int \sim \mathrm{z} \sim \mathrm{sZ} \sim \mathrm{zS}$ & $\mathrm{z}$ & {$[\mathrm{z}]$} \\
\hline
\end{tabular}




\begin{tabular}{|l|l|l|}
\hline$x$ & $k s$ & {$[k s]$} \\
\hline$q$ & $k(h)$ & {$[q]$} \\
\hline$w$ & $v$ & {$[w]$} \\
\hline
\end{tabular}

İncelemeye konu edilen metinlerde görülen yazım özelliklerine göre harf / ses eşlemeleri Tablo 1'de gösterilmiştir. Tablonun son sütünunda ilgili sesin IPA kartında yer alan gösterimlerine de yer verilmiştir. İlgili eşlemelerde kesin sınırlar ve ölçütler bulunmaz. Her bir eser bağlamında eşlenikler tablosunda değişmeler bulunacağı hususunun göz önünde bulundurulması gerektiği söylenmelidir.

Tablo 1'e göre harf / ses eşlemelerinde ünlüler bakımından 5 ünlüye \{a, e, i, o, u\} dayanan setin etkisi görülmektedir. Ünlü setinde bulunmayan $\{1, \ddot{o}, \ddot{u}\}$ seslerini karşılamak için diğer ünlülerden daha fazla yararlanılmıştır. ÇYM’lerde ilgili ünlüleri karşılamak üzere ikili ünlüler de (kayan ünlü, diftong) < ia, ie, io, iu, ÿe, oe, oi, ou, ue> kullanılmıştır: honkiar "hünkâr", aliech "aleyh", gÿendi "kendi", giege "gece”, ziolmech "çömlek", ogius "öküz”, gois "göz", bou "bu”, khuele "köle" vb. Ara bir ünlü veya alt sesbirimi işaret ettiği şeklinde yorumlanabilen ikili ünlü bulunan yazımlar, sesletimdeki ara formları yansıtan bir özellik olarak değerlendirilebilir. Ayrıca gerek ses olayları gerekse de kullanıcıya bağlı nedenlerle sesletime ait özelliklerin yansıtılması maksadıyla kullanılan ikiz ünlüler <aa, ee, uu> bulunur: taari “tanrı", beeg "bey”, chuuli "köylü” vb.

Tablo 1'e göre ünsüzler bakımından /k/ ve /g/ ünsüzlerinin art ve ön ünlülü sesletimlerine bağlı olarak daha fazla ses değişkenine sahip olduğu görülmektedir: Ön ünlülü kullanımı göstermek üzere / $\mathrm{k} /$ için $<\mathrm{c} \sim \mathrm{c} \sim \mathrm{k} \sim \mathrm{ki} \sim \mathrm{ch} \sim \mathrm{ck} \sim \mathrm{ki} \sim \mathrm{kk} \sim \mathrm{ckh}>\mathrm{ve} / \mathrm{g} /$ için $<\mathrm{g} \sim \mathrm{gc} \sim \mathrm{gh} \sim \mathrm{gi} \sim \mathrm{gi} \sim \mathrm{gk} \sim \mathrm{gy} \sim$ gÿ $\sim$ ghi $>$ harf ve harf bileşikleri kullanılmıştır. Art ünlülü kullanımı göstermek üzere sırasıyla $<\mathrm{c} \sim \mathrm{ch} \sim \mathrm{q}>\mathrm{ve}<\mathrm{gh}>\mathrm{harf}$ ve harf bileşiklerinin kullanıldığı görülmektedir. Harf ve ses eşlemesinde kendisini temsil etmek üzere $<\mathrm{b}, \mathrm{l}, \mathrm{m}, \mathrm{n}, \mathrm{p}, \mathrm{r}, \mathrm{t}>$ harfleri ilgili sesi karşılamak üzere kullanılmıştır. Harf / ses eşlemelerinde ünsüzler bakımından /ç/ sesi için $<\mathrm{c} \sim \mathrm{c} \sim \check{\mathrm{c}} \sim \mathrm{z} \sim \mathrm{cc} \sim \mathrm{ch} \sim \mathrm{ci} \sim \mathrm{cs} \sim \mathrm{c} \int \sim \mathrm{cz} \sim \mathrm{ts} \sim \mathrm{t} \int \sim \mathrm{tz} \sim \mathrm{zh} \sim \mathrm{t}$ ch $>$ şeklinde olmak üzere 15 harf veya harf bileşiği kullanılmıştır. Sırasıyla /ş/, /k/, /g/ ünsüzleri için kullanılan karakterlerin diğer ünsüzlere göre sayıca fazla olduğu görülmektedir.

\section{Yazım şekline bağlı sesletim özellikleri}

ÇYM’lerde sıklıkla rastladığımız bir özellik, aynı kavrama işaret eden sözcüklerin aynı metinde birden fazla şekilde yazılmasıdır. Bu durum, bazen kaydedici ya da musahhihten kaynaklanan sebeplere bağlansa da sesletim ve yazım arasındaki ilişkiden de kaynaklanıyor olabilir. Standart bir yazımın olmaması, bazen ihmal edilebilen hususiyetler, sonradan yazıya geçirilenle o anda yazılan arasındaki doğal farklar, konuşma temposundaki değişimler, iletinin değeri, bilgi yapısına bağlı değişimler, doğrudan sesle ilgili farklılıklar, ulamalar vb. bu çok katmanlı yazımın nedenleri arasında sayılabilir. Sayılan nedenlerden hangisinin ağır bastığı çok yönlü bir araştırmayı gerektirir. Bu makalede ÇYM’ler açısından yazımda görülen çok katmanlılık, konuşma dilinin yazıma etkisi bağlamında ele alınmıştır.

\subsection{Bitişik yazıma bağlı sesletim özellikleri}

ÇYM’lerde bitişik yazılan kelime ve eklerin çok sayıda örneği bulunmaktadır. Bu durum, sesletim ve yazım arasındaki ilişkiyi gösteren bir özelliktir. Standart yazım özelliklerinin zamanla geliştiği göz önünde bulundurulduğunda sesletime uygun yazma ihtiyacı bitişik yazımla giderilmiş olmalıdır. Bitişik yazılan örnekler arasında niteleyici sözcükler, isim, sıfat tamlamaları, sayı grupları, edatlar,

\footnotetext{
RumeliDE Dil ve Edebiyat Araştırmaları Dergisi Osmanağa Mahallesi, Mürver Ciçeği Sokak, No:14/8 Kadıköy - İSTANBUL / TÜRKIYE 34714 e-posta: editor@rumelide.com tel: +90 $5057958124,+902167730616$ 
soru ekleri, ek fiil ve yardımcı fiillerin ve anlamsal kaynaşmayı gösteren sözcük gruplarının ön sırada olduğu görülmektedir.

Örnekler, incelenen metinlerdeki söz varlığının önemli bir kısmını yansıtmaktadır. Ancak 16. yy. için söz varlığının diğer dönemlere göre daha az olması örneklerin dağılımında etkili olmuştur. 17. yy.a ait eserlerde niteleyiciler daha fazla bitişik yazılmışken 18. yy.da edatlar daha fazla bitişik yazılmış görünmektedir. Karşılaştırıldığında birinci durumda sözlü dil, konuşma dili; diğerinde yazılı dil öncelikli görülmüştür. Bu durum, konuşma dilinden yazı diline geçişin ve yazı dili standartlaşmasının bir yansıması olarak da kabul edilebilir.

İlgili yüzyıllara ait eğik yazıyla verilen örneklerin yanında parantez içinde ayrı yazılmış günümüzdeki kullanım şekli, sıklı̆̆ı, eserin adı, tarihi ve sayfa sayısı da gösterilmiştir. Örneklerde artan sırada eser yllı ve alfabetik örnek sıralaması yapılmıştır. Ünlüler için V (vokal), ünsüzler için K (konsonant) kısaltmaları kullanılmış, sözcük || simgesi içinde ve sözcük sonu .X, sözcük başı ise $\mathbf{X}$. şeklinde gösterilmiştir.

\subsubsection{Bitişik yazılan niteleyici sözcük ve yapılar}

ÇYM'lerde bitişik yazılan niteleyici sözcükler genellikle sıfat tamlamaları şeklindedir. Özellikle 17. yy.da ve daha az olmak üzere 18.yy.da görülür. Sıklık bakımından her, en, iyi, bu, o sıfatları ve ehl - $i$ tamlananı kendisinden sonra gelen sözcüğe bitişik yazılmıştır. İlgili sıfatlar genellikle derece, işaret vb. anlam ilgileri kurmaktadır. Konuşma dilinde niteleyici sözcüklerin kendinden sonraki sözcüğe yaklaştırılarak sesletilmesi yazımda da benzer bir tercihi yansıtmış olmalıdır.

\section{6. yy.}

chrichbir (kırk bir) [1] ON/1527. I

chrichvz (kırk üç) [1] ON/1527. I

\section{7. yy.}

echlisuneti (ehl-i sünnet) [1] ILT/1612

egriottur (eğri ottur) [1] ILT/1612 (a/125)

evifini (ev issi) "ev sahibi” [1] ILT/1612 (a/156)

herchinase (her kimse) [1] ILT/1612 (a/o54)

herdaim (her daim) [1] ILT/1612 (a/050)

herkhischi (her kişi) [1] ILT/1612 (a/o57)

herkim (her kim) [1] ILT/1612 (a/o77)

herne (her ne) [2] ILT/1612 (a/o16)

hernere (her nere) [1] ILT/1612 (a/102)

herneste (her nesne) [1] ILT/1612 (a/o66)

eigiami (iyi cami) [1] DDLT/1641

eifultan (iyi sultan) [1] DDLT/1641

agasamoglanlar (acem oğlanı) [1] CFT/1672 (b7/168)

atmejdana (at meydanı) [1] CFT/1672 (b6/138)

bazikifiler (bazı kişiler) [1] CFT/1672 (b8/427)

berberbafi (berber başı [1] CFT/1672 (b7/297)

birdacha (bir daha) [1] ILT/1612 (a/209)

\begin{tabular}{|c|c|}
\hline Adres & \\
\hline RumeliDE Dil ve Edebiyat Araşttrmalar De & iDE Journal of Language and Literature Studies \\
\hline manağa Mahallesi, & ă̆a Mahallesi, Mürver Çiçeği Sokak, No:14/8 \\
\hline Kadıköy - İSTANBUL / TÜRKIYE 34 & - ISTANBUL / TURKEY 34714 \\
\hline $\begin{array}{l}\text { e-posta: editor@rumelide.com } \\
\text { tel: }+905057958124,+90216773 \text { o } 616\end{array}$ & $\begin{array}{l}\text { editor@rumelide.com, } \\
\text { +90 } 5057958124,+90216773 \text { o } 616\end{array}$ \\
\hline
\end{tabular}


bukadar (bu kadar) [16] CFT/1672 (b1/o20, b2/o31, b2/o43, b3/o55, b4/o74, b5/100, b6/142, b7/170, b7/196, b7/211, b7/215, b7/340, b7/346, b8/366, b8/421, b8/490)

büzeman (bu zaman) [1] CFT/1672 (b2/034)

dilßahibi (dil sahibi) [1] CFT/1672 (b5/09o)

dortjuz (dört yüz) [1] CFT/1672 (b7/238)

ehlifeßat (ehli fesat) [1] CFT/1672 (b8/372)

ehliilm (ehli ilim) [1] CFT/1672 (b8/405)

ehliirz (ehli rrz) [1] CFT/1672 (b7/342)

elcsibeg (elçi bey) [1] CFT/1672 (b7/338)

elßözi (el sözü) [1] CFT/1672 (b7/249)

enbas (en baş) [1] CFT/1672 (b6/142)

enßonra (en sonra) [1] CFT/1672 (b1/oo8)

hergiün (her gün) [1] CFT/1672 (b6/143)

herjerde (her yerde) [1] CFT/1672 (b3/055)

herkißile (her kişi ile) [1] CFT/1672 (b2/043)

herfej (her şey) [1] CFT/1672 (b7/254)

hervakte (her vakit) [1] CFT/1672 (b6/144)

herzaman (her zaman) [1] CFT/1672 (b6/112)

herzeman (her zaman) [3] CFT/1672 (b4/o6o, b6/114, b6/141)

herßene (her sene) [1] CFT/1672 (b7/281)

nehadar (ne kadar) [1] CFT/1672 (b8/421)

nefekil (ne şekil) [1] CFT/1672 (b8/405)

ogünde (o günde) [1] CFT/1672 (b7/249)

okaldar (o kadar) [1] CFT/1672 (b7/238)

oldemde (o dem) [1] CFT/1672 (b7/341)

olkifi (o kişi) [1] CFT/1672 (b7/347)

olßahat (o saat) [1] CFT/1672 (b3/045)

pekhazi (pek hazzl) 1] CFT/1672 (b4/o61)

peklazumdurki (pek lazımdır ki) [1] CFT/1672 (b5/091)

serbetc/ibafi (şerbetçi başı) [1] CFT/1672 (b7/297)

solkadar (şu kadar) [3] CFT/1672 (b2/035, b2/o35, b5/o86)

fausbafa (çavuş paşa) [1] CFT/1672 (b5/095)

terzi(a)bafi (terzi başı) [1] CFT/1672 (b7/297)

ucsbasli (üç başlı) [1] CFT/1672 (b6/139)

18. yy.

enbüjük (en büyük) [1] BGD/1781 (57)

enejifini (en iyisini) [1] BGD/1781 (78)

hernek'i (her ne ki) [1] BGD/1781 (v/4)

nékadar (ne kadar) [5] BGD/1781 (57, 86(3), 91)

ondokúzdur (on dokuz) [1] BGD/1781 (97)

öjlejérge (öyle yere) [1] BGD/1781 (52)

hepbirdur (hep birdir) [1] GT/1789 (120)

herbirine (her biri) [1] GT/1789 (168)

olvakt (o vakit) [1] PGT/1794 (710)

òlzaman (o zaman) [1] PGT/1794 702 
Ses özellikleri bakımından iki sözcügün birleştiği eklemlerde durum şöyledir:

$$
\begin{aligned}
|. K+K .| & / \mathrm{r}-\{\mathrm{k}(4), \mathrm{n}(4), \mathrm{d}(2), \mathrm{s}(2), \mathrm{z}(2), \mathrm{b}, \mathrm{j}, \mathrm{g}, \mathrm{v}\} / \\
& / \mathrm{l}-\{\mathrm{s}(3), \mathrm{k}(3), \mathrm{d}, \mathrm{v}, \mathrm{z}\} / \\
& / \mathrm{n}-\{\mathrm{b}(2), \mathrm{d}, \mathrm{s}\} / \\
& / \mathrm{c}-\mathrm{k}-\mathrm{p}-\mathrm{r}-\mathrm{s}-\{\mathrm{b}\} \mathrm{ve} / \mathrm{k}-\mathrm{l} /, / \mathrm{t}-\mathrm{m} /, / \mathrm{t}-\mathrm{j} /, / \mathrm{y}-\mathrm{g} /, / \mathrm{y}-\mathrm{s} /
\end{aligned}
$$

Bu türden birleşmede ilk sözcügün sonunda daha sık görülen $\{l, n, r\}$ ünsüzlerinin ortak özelliği $\{t, d\}$ sesleri ile beraber dişsil ünsüz kategorisinde yer almalarıdır (Özsoy, 2006, s. 33). İkinci sözcügün başında yer alan ünsüz seti arasında görülen $\{\mathrm{d}, \mathrm{s}, \mathrm{z}, \mathrm{n}\}$ ünsüzleri ise çıkış yeri bakımından $\{\mathrm{l}, \mathrm{n}, \mathrm{r}\}$ ünsüzleri ile beraber diş eti ünsüzleri arasında görülür (Aksan, 2003, s. 36). Bu ünsüzlerin sesletiminde ses telleri de titreşir. Demircan (2015), "Bir ünsüz gibi çıkıp da bir ünlü gibi görev yapan /l, m, n, r/ gibi seslere yarı - ünsüz dense yeridir.” (s. 25) diyerek ilgili ünsüzlerin işlevine vurgu yapmıştır. Bu işlevin kendinden sonraki ünlüyü sesletmede hazırlık sağlayacă̆ı görülmektedir. Böylece sesletim bakımından dil ucunun üst diş etine değdiği yerde oluşan ve çıkış yeri yakın iki ünsüzün (alveolar - dişyuvasıl ünsüzler) aralıksız kullanıldı̆̆ı tasavvur edilebilir.

Ötümsüz \{p, ç, t, k\} ünsüzlerinin sonda bulunması ve kendinden sonra gelen ünsüzü benzetmesi Türkçe için tipik bir özelliktir. Örneklerde ötümsüz sert ünsüzlerden sonra genellikle çift dudak /b/ ötümlü ünsüzü gelmiştir. Bu ünsüzlerin ortak özelliği \{c, d, g\} ünsüzleri ile beraber çıkış biçimi bakımından süreksiz olmalarıdır. Demircan (1981), seslemleme ile ilgili makalesinde ünsüz benzeşmeleri başlığı altında “(...) benzeşme seslemden sesleme geçişteki kısıtlamalar gereği, ayırıcı özelliklerin uyuşması, bir anlamda düzlenmesidir. Bu bağlamda yavaş ve hızlı sesletim arasında bir ayrım gözetmek yerinde olacaktır.”(s. 52) demektedir. Konuşma diline özgü hızlı sesletmeler bu türden bitişik yazılmış örnekleri doğuran nedenler arasında saylabilir. Sesletimlerde kısıtlamaların azaltılması veya sesletimin lehine düzenlenmesi beklendiğinden çıkış yeri yakın iki ünsüzün aralıksız kullanımı da bu bağlamda anlaşılır olmaktadır.

$$
\begin{gathered}
|. V+\mathrm{K} .| / \mathrm{i}-\{\mathrm{s}(3), \mathrm{b}(3), \mathrm{c}, \mathrm{k}\} / \\
/ \mathrm{e}-\{\mathrm{h}, \mathrm{j}, \mathrm{s}, \mathrm{k}\} / \\
\\
/ \mathrm{o}-\{\mathrm{g}, \mathrm{k}\} / \\
\\
/ \mathrm{u}-\mathrm{k} /, / \mathrm{u}-\mathrm{z} /
\end{gathered}
$$

Sonda bulunan ünlü genellikle $\{\mathrm{i}, \mathrm{e}, \mathrm{o}\}$ ve eklemlendiği ünsüzler genellikle $\{\mathrm{b}, \mathrm{k}, \mathrm{s}\}$ şeklindedir. Ortak özellikler tesis etmekten uzak bir dağılım göstermektedirler. Ancak bir tasnif biçimi bu zorluk hakkında bilgi verebilir. "Chomsky - Halle (1968) çıkış yeri ayrımlarını şöyle saptamıştır. Ağız tavanını, dişseti / damak arasından ikiye bölen ön özelliğine göre ünsüzlerin ayrımında ön özelliği görülmeyen ünsüzler şu şekildedir: \{r, c, y, ş, j, k, g, ğ, h\}” (Demircan, 2015, s. 33). İlgili örnekler bağlamında genellikle $\{i$ ve e\} ön ünlülerinin ardından gelen ilgili ünsüzlerin damakta sesletildiği görülmektedir.

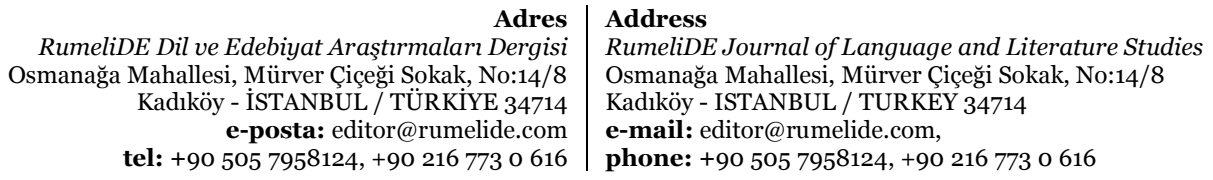


Daha az sayıda olmak üzere |.V + K.| i - \{i(2), o $\}$ ve $|. K+V| / k-.u /, / m-~ o /, / n-e /, / v-i /$ dizilimleri de görülmektedir. Birincisi iki aynı ünlünün sesletimini yansitır ki bu ehliilm, ehliirz örneklerinde gösterilmeyen gırtlaksıl ayın sesinin / / / etkisi hesaba katılmalıdır. Bu bakımdan |.V + K.| dizilimine daha uygun olan bu türden kalıplaşmış örneklerde ünlünün uzadığı söylenebilir. Dizilim bakımından ulamayı sağlayan |.K + V.| grubunda sınırlı sayıda örnek görülmektedir. Bunun sebebini sözcüksel bağlamda ele almak daha açıklayıcıdır. Banguoğlu (1974), belirtme öbeklerinde vurguyu değerlendirirken "Belirtme öbeklerinde vurgulu hece hemen daima belirtenin vurgulu hecesidir." (s. 119) tespitinde bulunur. Buna göre dizilimlerde birinci ögenin yani niteleyicinin son hecesinde biriken vurguyu azaltarak ikinci ögeye yani nitelenene yaklaştırılması seslik unsurlara göre daha belirleyici görünmektedir.

\subsubsection{Bitişik yazılan edat ve bağlaçlar}

ÇYM'lerde bitişik yazılan başta edatlar ve daha az olmak üzere bağlaçlar görülmektedir. Bitişik yazılmış örnekler, metinlerdeki sözcük sayısına bağlı olarak, 17. ve 18. yy.da 16.yy.dan daha fazla kullanılmıştır. Sıklık bakımından genellikle ile, için, dek edatlarının kendinden önce gelen sözcüğe bitişik yazıldığı görülmektedir. İlgili edatlar birliktelik, sınır, neden vb. anlam ilgileri kurmaktadır. Konuşma dilinde sesletimin genellikle bağlı sözcükle olduğu edatların yazımda da bu özelliği yansıtmak üzere bitişik yazıldığı görülmektedir.

\section{6. yy.}

rhuchile (ruh ile) [1] TG/1581 (7/ah)

anunile (onun ile) [1] TG/1581 (4/ah)

anunontzin (onun için) [1] TG/1581 (7/ah)

atemlerile (âdemler ile) [1] TG/1581 (5/ah)

bilimegitzin (bilmek için) [1] TG/1581 (3/ah)

elmile (ilim ile) [1] TG/1581 (5/ah)

keltigitzun (geldiği için) [1] TG/1581 (9/ah)

olthugutzin (olduğu için) [1] TG/1581 (1/ah)

tzurmile (cürüm ile)[1] TG/1581 (10/ah)

\section{7. yy.}

hadissatile (hadisat ile) [1] ILT/1612 (a/067)

iaramasile (yaramaz ile) [1] ILT/1612 (a/218)

lutfile (lütuf ile) [2] ILT/1612 (a/182)

oldurkhi (odur ki) [1] ILT/1612 (a/o31)

zamanedeh (zamana dek) [2] RGT/1630 (95, 95)

andanoturi (ondan ötürü) [1] CFT/1672 (b8/425)

$\operatorname{dimi\beta ki}$ (demiş ki) [1] CFT/1672 (b6/124)

dinßiziken (dinsiz iken) [1] CFT/1672 (b8/369)

edebile (edep ile) [1] CFT/1672 (b8/370)

emriile (emri ile) [2] CFT/1672 (b7/210, b8/442)

gyöziile (gözü ile)[1] CFT/1672 (b8/405)

haftaiadak (haftaya dek) [1] CFT/1672 (b8/427)

hafile (haz ile) [1] CFT/1672 (b7/175)

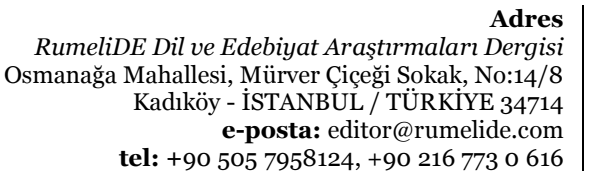

Address

RumeliDE Journal of Language and Literature Studies

Osmanağa Mahallesi, Mürver Çiçeği Sokak, No:14/8

Kadıköy - ISTANBUL / TURKEY 34714

e-mail: editor@rumelide.com,

phone: +90 505 7958124, +90 2167730616 
hoslugiile (hoşluk ile) [1] CFT/1672 (b3/053)

ialanile (yalan ile) [1] CFT/1672 (b7/341)

igsazetile (icazet ile) [1] CFT/1672 (b5/108)

kaldiringsedek (kaldırıncaya dek) [1] CFT/1672 (b5/o86)

kilitfile (kllıc ile) [1] CFT/1672 (b3/o53)

kifïile (kişi ile) [2] CFT/1672 (b5/102, b8/369)

kulagile (kulak ile) [1] CFT/1672 (b8/405)

lefile (leş ile) [1] CFT/1672 (b8/426)

mertebeile (mertebe ile) [1] CFT/1672 (b7/338)

mugsizatile (mucizat ile) [1] CFT/1672 (b8/442)

neitzün (niçin < ne + için) [1] CFT/1672 (b1/o20)

nenungibi (ne(nun) gibi [1] CFT/1672 (b1/o07)

ockile (ok ile) [1] ILT/1612 (a/o97)

ondàiken (onda iken) [1] BGD/1781 (82)

oßmanliile (Osmanlı ile) [2] CFT/1672 (b7/154, b7/216)

perdaile (perde ile) [1] CFT/1672 (b6/141)

symdiedek (şimdiye dek) [3] CFT/1672 (b5/o82, b7/171, b8/472)

ülefeile (ulufe ile) [1] CFT/1672 (b7/235)

Babahadak (sabaha dek) [1] CFT/1672 (b8/408)

\section{8. yy.}

cekilingedek (çekilinceye dek) [1] BGD/1781 (90)

chaftáilen (hasta ilen) [1] BGD/1781 (97)

damlasiilan (damlası ilen) [1] BGD/1781 (66)

denizédek (denize dek) [1] BGD/1781 (93)

edrinejedek (Edirne'ye dek) [1] BGD/1781 (106)

efpablerinizile (esbaplarmız ile) [1] BGD/1781 (109)

$g^{i}$ ereigiibi (gereği gibi) [1] BGD/1781 (95, v/34)

giünédek (güne dek) [1] $\mathrm{BGD} / 1781$ (52)

jaramazlàrilen (yaramazlar ilen) [1] BGD/1781 (66)

jaziilen (yazı ilen) [1] BGD/1781 (v/4)

jóghifa (yok ise) [1] BGD/1781 (64)

kalémile (kalem ile) [1] BGD/1781 (96)

kiàghydlárilen (kă̆ıtlar ilen) [1] BGD/1781 (90)

kolajlighile (kolaylık ile) [1] BGD/1781 (93)

marifetiilen (marifeti ilen) [1] BGD/1781 (53)

menzilile (menzil ile) [1] BGD/1781 (53)

öjléife (öyle ise) [1] BGD/1781 (96)

pilafile (pilav ile) [1] BGD/1781 (109)

rahátile (rahat ile) [1] BGD/1781 (67)

faghlygioklarile (sağlıcaklar ile) [1] BGD/1781 17

Jahattàdak (saata dek) [1] BGD/1781 (85)

fangiilan (sancı ilen) [1] BGD/1781 (97)

Sefaile (sefa ile) [1] BGD/1781 (111)

beghirlerile (beygirler ile) [1] GT/1789 (116)

innayetiile (inayeti ile) [1] GT/1789 (120) 
iradetile (iradet ile) [1] GT/1789 (163)

kolayile (kolay ile) [1] GT/1789 (164)

stamboladek (İstanbul'a dek) [1] GT/1789 (118)

varindfchedek (varıncaya dek) [2] GT/1789 $(116,119)$

chatrnỳićiün (hatırın için) [1] PGT/1794 (700)

ederlerkien (ederler iken) [1] PGT/1794 (701)

sebebi" ile (sebep ile) [1] PGT/1794 (714)

seninićiün (senin için) [1] PGT/1794 (700)

Ses özellikleri bakımından iki sözcüğün birleştiği eklemlerde durum şöyledir:

$$
\text { |.K + V.| /r (5), t (5), s (4), g (4), n (4), m (3), f (2), k (2), ğ (2), z (2), b, c, h, l, y \{i\} /g- u/, /n- o/, /c- e/ }
$$

Edatların ilk ünlüsü /i/ düz dar ünlüsüdür. Bu bakımdan ilk sözcük sonunda vurgu ve hece doruğundan kaynaklanan çevresel şartlar ulamayı kolaylaştırmaktadır. Çok sayıda örneğin bu grupta görünmesi bu temel bağıntının gereği olmalıdır. Edatlar, eklendiği sözcügün son hecesindeki vurguyu azaltabilir senin $\uparrow$ ile $\nmid \neq$ seninile $\downarrow$ ki böylece hece doruk sayısı da azalır. Bu duruma bağlı olarak edatın baştaki ünlüsü düşürülebilir: seninle. Bu bağlamda edatların konuşma dilinde sesletim birliğine elverişli yapısal imkânlar sunduğu görülmektedir.

Ünsüzler sınıfı bakımından genellikle $\{r, t, s, g, n, m, f, k, \breve{g}$, z\} ünsüzleri kullanılmıştır. Sesletim bakımından ünsüzlerin niteliği düz dar ünlüye bağlanma şartını yerine getirmeleridir. $O$ halde ünsüz niteliği ikincil bir öneme sahiptir. Ayrıca sesletim yeri bakımından /i/ ünlüsü ile yakın bölgede oluşan dişyuvasıl $\{\mathrm{t}, \mathrm{d}, \mathrm{s}, \mathrm{n}, \mathrm{l}, \mathrm{r}\}$ ünsüzlerinin $\{\mathrm{k}, \dot{\mathrm{g}}\}$ art damak ünsüzlerine göre daha slk birleşmesi de beklenebilir.

$|. V+\mathrm{V}$.$| /i (12), e (4), a (4)\{i\}$

İki /i/ düz - dar ünlüsünün art arda gelmesi sesletimde ünlü uzamasına veya ikinci ünlünün /y/ yarı ünlüsü ile nöbetleşmesine neden olabilir. Ünlülerin yazımda ikisinin de gösterilmesi sesletim - yazım bağlantısını işaret etmektedir. Örneklere göre $\{a$, e\} ünlüleri de eklem yerinde görünmektedir. Edatların Arap harfli imlada eklendiği sözcükle birlikte yazılmasından dolayı ilgili örneklerde bu kalıplaşmanın devamı niteliğinde Arap harfli yazımın etkisi söz konusu edilebilir.

$|. \mathrm{V}+\mathrm{K}.| / \mathrm{e}(7), \mathrm{a}(4)\{\mathrm{d}\}, / \mathrm{i}-\mathrm{g} /$

|.K $+\mathrm{K} . \mid / \mathrm{s}-\mathrm{k} /, / \mathrm{r}-\mathrm{k} /, / \mathrm{n}-\mathrm{g} /$

Ünlü - ünsüz birleşiminde geniş ünlüler \{a, e\} kendinden sonra gelen /d/ ötümlü dişyuvasıl ünsüzüne bağlanmıştır. Bu bağlanmada seslik özellikler ikinci plandadır. Ünsüzle başlayan tek bir edat bulunur: dek. Sözcüksel uyum, yazllışta bu türden sessel birleşimleri doğurmuştur.

\subsubsection{Bitişik yazılan ek- fiil ve yardımcı fiiller}

ÇYM’lerde bitişik yazılan ek fiilli ve yardımcı fiillerle kurulan birleşik fiil yapıları görülmektedir. Bitişik yazılmış örneklerde i- ek fiili genellikle belirli geçmiş zaman, belirsiz geçmiş zaman ve şart ekleri biçiminde iken et-, ol-, eyle- yardımcı filleri daha sıklıkla kullanılmıştır. Bu türden bitişik yazılmış örnekler genellikle 17. ve 18. yy.da görülmektedir. Konuşma dilinde kalıplaşmış halde kullanılan bu

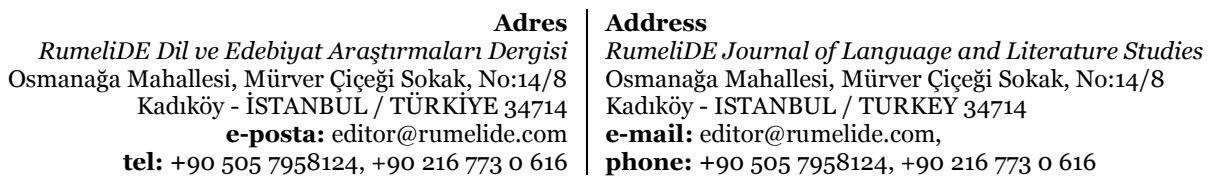


türden yapılar, sesletimin bu özelliğine uygun biçimde bitişik yazılmış olmalıdır. Seslik bakımdan ilgili fiillerin ilk sesi \{e, o\} ünlüleridir. Kendisinden önceki ünsüze ulama ile bağlanma imkânı verir ve vurguya azaltır veya yayar. Bu bakımdan hece doruğundaki azalma sesletimdeki birliğe elverişli imkân sağlar. Bu uygun özelliklerin birliği yazıma yansımıştır.

16. yy.

inanmaslariti (inanmazlar idi) [1] TG/1581 (4/ah)

17. yy.

gafilifem (gafil isem) [1] ILT/1612

gutscholakhi (güç ola ki) [1] ILT/1612 (a/o76)

jarolfe (yar ol-) [1] ILT/1612 (a/190)

noscheder (nuş et-) [1] ILT/1612 (a/o89)

pagkolaßin (pak ol-) [1] ILT/1612

Sabuneder (zebun et-) [1] ILT/1612 (a/171)

dirigbujurmaia (diri buyur-) [1] CFT/1672 (b5/099)

edaideim (eda et-) [1] CFT/1672 (b5/089)

etmemisleriße (etmemişler ise) [1] CFT/1672 (b5/108)

galibolanun (galip ol-) [1] CFT/1672 (b7/155)

kailolmazßen (kail olma-) [1] CFT/1672 (b3/o55)

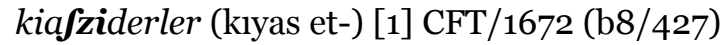

kiaßejleme (klyas eyleme-) [1] CFT/1672 (b7/234)

kulolduklarina (kul ol-) [1] CFT/1672 (b7/155)

lazumolagsak (lazım ol-) [1] CFT/1672 (b1/015)

lutfieyle (lütuf eyle-) [1] CFT/1672 (b1/o11)

methedemeürüm (meth edeme-) [1] CFT/1672 (b8/369)

neol $\beta a$ (ne ol-) [1] CFT/1672 (b5/110)

olinmisidüm (olunmuş idim) [1] CFT/1672 (b5/o82)

telefolur (telef ol-) [1] CFT/1672 (b1/oo8)

Rabridigsi (sabır edici) [1] CFT/1672 (b5/090)

Boalideim (sual et-) [2] CFT/1672 (b1/o05, b1/o11)

18. yy.

afietlérola (afiyetler ola) [1] BGD/1781 (88)

biliridim (bilir idim) [1] BGD/1781 (50)

cekmišolàidi (çekmiş ol-) [1] BGD/1781 (95)

chairola (hayır ola) [2] BGD/1781 (90(2)

ciòkola (çok ola) [1] BGD/1781 (77)

etmemifcidim [1] (etmemiş idim) BGD/1781 (86)

gielmedimise (gelmedim ise) [1] $\mathrm{BGD} / 1781$ (77)

$g^{i}$ erékidin (gerek idin) [2] BGD/1781 $(84,85)$

gierékife (gerek ise) [1] BGD/1781 (54)

hararetímidi (hararetim idi) [1] BGD/1781 (97)

iftéridim (ister idim) [1] BGD/1781 (77) 
jazmyśidim (yazmış idim) [1] BGD/1781 (v/3)

oldùife (oldu ise) [1] BGD/1781 111

razola (razı ol-) [1] BGD/1781 (107)

terléséidim (terslese idim) [1] BGD/1781 (99)

vurmúšola (vurmuş ol-) BGD/1781 (95)

\subsubsection{Bitişik yazılan soru eki}

ÇYM’lerde soru eki kendinden önceki sözcüğe bitişik yazılır ve ÇYM'lerde sesletimin ve yazımın iç içe geçtiği örnekler soru ekli yapılarda da görülmektedir. Ek yardımıyla soru yapımında vurgu, ekten önceki hecede yoğunlaşır. Soru ekinin ayrı yazılması bugünkü imlanın gereğidir. Bitişik yazılmış örneklerde konuşma dilinin hızının etkisinin yazıma yansıdığı söylenebilir. Ayrıca Auer (1990), Türkçenin sözdizimsel kaymalarından birisi olarak $\{\mathrm{mI}\}$ soru ekinin (enklitik) konumundan ${ }^{4}$ yola çıkarak değerlendirme yapmaktadır (s. 286 - 287). Soru ekinin bitişik yazılmasının sadece sesletimi değil bilgi yapısına bağlı sözdizimsel bir özelliği de işaretlediği söylenebilir. Örnekler bağlamında iki durumun birlikte değerlendirilmesi yerinde görünmektedir.

16. yy.: 16. yy.da incelediğimiz eserlerde görülmez.

\section{7. yy.}

bulunurmi (bulunur mu) [2] CFT/1672 (b4/o59, b4/074)

erkekmidür (erkek midir) [1] CFT/1672 (b8/426)

edermißin (eder misin) [1] CFT/1672 (b4/06o)

giaurmißin (gâvur musun) [1] CFT/1672 (b1/o04)

ejimißin (iyi misin) [1] CFT /1672 (b1/o02)

\section{8. yy.}

bitmišmi (bitmiş mi) [1] BGD/1781 (86)

bulunurmy (bulunur mu) [1] BGD/1781 (107)

edermi (eder mi) [4] BGD/1781 (v/32(3), v/33)

guaourmi (gâvur mu) [1] GT/1789 112

hazyírmydyr (hazır mıdır) [1] BGD/1781 (85)

hofchmi (hoş mu) [1] GT/1789 110

chośnütmüfünüz (hoşnut musunuz) [1] BGD/1781 (111)

ejímidir (iyi midir) [1] BGD/1781 (87)

\subsubsection{Bitişik yazılan anlamca kaynaşmış yapılar}

ÇYM'lerde anlamsal birliği ve birlikte kullanımı yaygınlaşmış kimi yapıların sesletime uyarak bitişik yazıldığı görülmektedir. Bu yapılar arasında kısa emir yapıları varget yanında deyimlerin Birßaklaian, hberuuerur, kandukmecten vb. kalıplaşarak sesletimi yazımda bitişikliği doğurmuş olmalıdır. Bazı

$4 \quad$ Auer (1990) ilgili değişimlerin gerçekleştiği yüklem sonrası konum için şu örnekler üzerinden tartışmayı yürütür: (37) bu firma seni tekrar işe alacak mı almıyacak mı önemli // (38) İşte agbiim(in) bir dükkäni vardı zaten o da işliyor mu işlemiyor mu belli değildi çalışıp çalışmadığı // (39) bakıyor nasıl yaptıklarına iyi yapıyorlar mı nöbeti // (40) ya resmi mesmi benim hoşuma gitmedi mi şey yapmiyorum // (41) markları da bozdurdun mu bi(r) çuval Türk lirası geçiyor eline // (42) İsmail kahveye gitti mi sinırlı bir zaman içerisinde gidiyor geliyor // (43) elektrik kesildi mi oturursun alırsın tavlayı eline (s. $286-287$ ).

RumeliDE Dil ve Edebiyat Araşttrmaları Dergisi Osmanağa Mahallesi, Mürver Çiçeği Sokak, No:14/8 Kadıköy - İSTANBUL / TÜRKIYE 34714 e-posta: editor@rumelide.com tel: +90 505 7958124, +90 2167730616
Address

RumeliDE Journal of Language and Literature Studies

Osmanağa Mahallesi, Mürver Çiçeği Sokak, No:14/8

Kadıköy - ISTANBUL / TURKEY 34714

e-mail: editor@rumelide.com,

phone: +90 505 7958124, +90 2167730616 
durumlarda onijolda, fcejalma şeklinde bitişik yazılmış örneklerde kalem işlekliğinin etkisi de söz konusu edilebilir.

\section{6. yy.}

varget (var git) [1] ON/1527. I

\section{7. yy.}

azfajar (az say- [1] CFT/1672 (b5/o86)

hberuuerur (haber ver-) [1] ILT/1612

hißapagyelmez (hesaba gelmez) [1] CFT/1672 (b8/361)

kandukmecten (kan dök-) [1] ILT/1612

Birßaklaian (sir sakla-) [1] CFT/1672 (b5/o83)

tekdurmazfe (tek durma-) [1] CFT/1672 (b5/o84)

jangelur (yan gel-) [1] ILT/1612 (a/o43)

\section{8. yy.}

onijolda (onu yolda) [1] CFT/1672 (b1/o25)

fcejalma (şey alma-) [1] BGD/1781 (98)

\subsection{Ayrı yazıma bağlı sesletim özellikleri}

ÇYM’lerde konuşurun amacına, vurgusuna, iletişimin niteliğine, bağlama vb. bağlı olarak kimi yapıların sesletime uyarak ayrı yazıldığı görülmektedir. Bu yapılar arasında her kieś, o birlere örneğindeki gibi iki ayrı sözcük; $t$ fchikar maffen, tezanda iz, kulunuz iz örneklerindeki gibi fiil çekimli yapılarda kişi ekleri; do laschur, ot manlia, jaik hadi, nifci anladyghyny örneklerindeki gibi ilk heceyi diğerlerinden ayrı yazarak heceleyerek yazma şekilleri görülmektedir. İlgili örneklerin bitişik yazılanlarının yanında bu türden ayrı yazılan örneklerin de görülmesi musahhihe bağlanabilir. Aynı zamanda bu türden örneklerin yeni dil öğrenicisinin yazma alanındaki doğal çalışma denemeleri, sesletime ait özellikleri daha çok yansıtıyor olmalıdır. Standartların henüz oluşmadığı ÇYM’lerde konuşma dilinin kişisel kullanıma dair sesletim özellikleri gösterdiği ayrı yazılmış örneklerden anlaşılabilir. Gülsevin (2013), seslik değişimlerin sadece değişen sesi ilgilendirmediğini değişime uğrayan sesin bulunduğu "çevre şartı" ile ilgili olduğuna işaret etmektedir (s. 52). Çevre şartı sessel değişimin bağlam duyarlı olduğunu ve giderek sözcük, tümce, cümle düzeyine çlkarılabilecek bir ilginin bulunduğunu da göstermektedir. İlgili örnekler arasında yer alan her kieś > herkes, o birlere > öbür sözcüklerinin günümüzde bitişik yazılmaları sadece yazımı ilgilendiren bir değişimden ibaret olmayıp çevreye dair izler de taşımaktadır.

16. yy.: 16. yy.da incelediğimiz eserlerde görülmez.

17. yy.

tfchikar maffen (çıkarmasın) [2] ILT/1612 (a/220, a/220)

do laschur (dolaşır) [1] ILT/1612 (a/163)

ot manlia (Osmanlı) [2] CFT/1672 (b1/015, b3/o57)

ut schi (üçü) [1] ILT/1612 (a/o95)

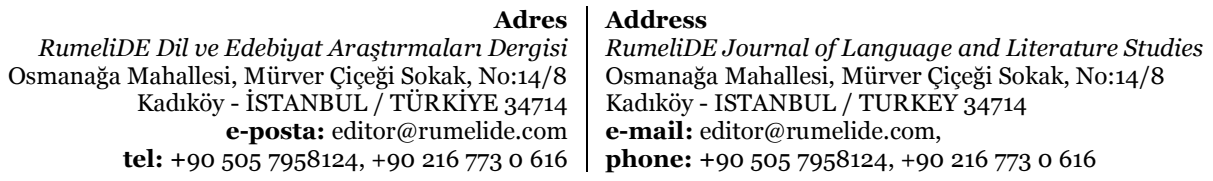


jang fchagi (yanşak) [1] ILT/1612 (a/o42)

jaik hadi (yaykadı) [1] ILT/1612 (a/204)

tezanda iz (tez andayız) "tez (vakitte) oradayız" [1] CFT/1672 (b4/o59)

18.yy.

her kieś (herkes) [3] BGD/1781 (85, 89, v/33)

kulunuz iz (kulunuzuz) [1] BGD/1781 (57)

nifci anladyghyny (nişanla-) [1] BGD/1781 (86)

o birlere (öbürlere) [1] BGD/1781 (v/30)

tabi - atï (tabiat) [1] PGT/1794 (704)

üleftir mislerdür (üleştirmişlerdir) [1] CFT/1672 (b3/051)

\subsection{Aynı eserde farklı yazıma bağlı sesletim özellikleri}

ÇYM'lerde aynı kavrama işaret etmek üzere kullanılan sözcüklerin yazımında kimi değişiklikler görülebilir. Bu değişikliklerin yansıdığı örnekleri Duman, M. (2008), seslilenmelerinde bir çeşitliliğin olduğu ve bu durumu bir karışıklık olarak nitelendirmenin doğru olmayacağı (s. 188) şeklinde değerlendirmiştir. Yazar, "Bunları, konuşma dilinin yarattığı çeşitlilik içinde, muhtemelen belli dil katmanlarında yaygınlık kazanmış, belli kullanım sıklığına ulaşmış telaffuz örnekleri” olarak ele almış ve makalesinde farklı yazılmış örneklere de yer vermiştir (s. 181 - 187). Duman, M. (2008), çok şekilli seslendirme ile ilgili görüşünü "Hiç olmazsa çalışmada standartlaşma sağlayacağız diye eserin dil özelliklerini kaybettiren bir tutumdan kaçınılması gerektiği anlayışını kazandırabilir.” (s. 188) şeklinde sürdürerek Türkçedeki meydana gelen fonetik gelişme ve değişimlerin (...) yazıya geçirilebileceği bu işleminse eskiden olduğu gibi yazıyı, konuşma telaffuzundan uzaklaşmaya götürecek süreçten kurtarabileceğine işaret etmektedir (s. 188). Tulum, M. (2011) de "Bu tür çalışmalarda farklı malzemeler üzerinden elde edilmiş sonuçların birbiriyle çelişmesi, ya da aynı metin içinde birbirinden ayrı değerler gösteren örnekler üzerine yapılan yorumların çeşitlenmesi işte hep bir metnin örneklerinin sınırladığı dar alan içinde kalınmış olmanın kaçınılmazlı̆̆ındandır. Bu tür çalışmalar hep birbirine atıfta bulunur, bu da ya kendi örnekleri üzerindeki değerlendirmeyi doğrulamak, ya da yine örneklerin ortaya koyduğu birbiriyle çelişen durumları açıklamak adına yapılır, çünkü karşılaşılan çelişkilerin yorumlanmasında güvenilir bir canlı kılavuz" (s. 6o - 61) olmamasına bağlayarak metinlerin doğal sınırlarına işaret etmektedir. Yazarların vurguladığı çok şekillilik ve çok katmanlılık incelediğimiz eserlerde de bulunmaktadır. Örneklerin değerlendirilmesinde "seslilendirme çeşitliliği”ni göstermek üzere eş zamanlı ve art zamanlı ses değişimleri birlikte değerlendirilmeye çalışılmıştır.

\subsubsection{Biçimsel seslik özellikler ve nöbetleşme}

Genellikle seslerin çıkış yeri dolayısıyla sesletimi bakımından yakın veya uygun uzaklıkta olanların yazımlarında çoklu yazım özelliği görülmektedir. Çoklu yazımın seslik temellerinin yanı sıra yazıma dair değişkeleri işaretlediği görüşünden hareketle biçimsel seslik özellikler başlı̆̆ altında gösterilmiştir. Demir, N. ve Yllmaz, E. (2011) tarafından hazırlanan “Türkçe Ses Bilgisi” adlı eserde ses olayları iki başlık altında değerlendirilmiştir. Ses olaylarının ikinci başlığında biçimsel ses bilgisine yer vermişler ve nöbetleşme ile ilgili özellikleri bu başlık altında incelemişlerdir (s. 106 - 127). İlgili nöbetleşme kavramını "nöbetleşme olarak alınan ses olayları (...) eklenmeye bağlı oldukları ve hem ses olayına uğramış hem de uğramamış biçimlerin dilde aynı anda kullanılıyor olması nedeniyle" (s.

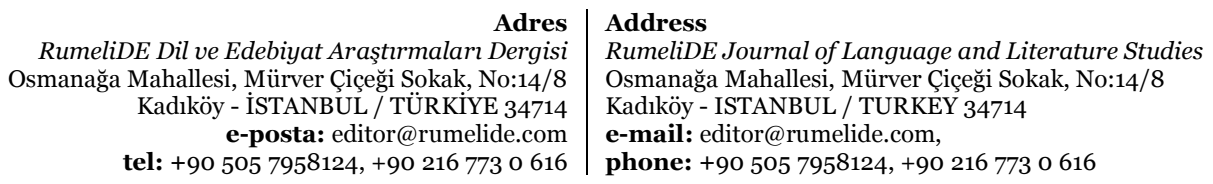


107) tercih ettiklerini belirtmişlerdir. Aynı eserde nöbetleşmenin geçici bir biçim olduğu "belli bir morfofonemik çevrede kullanılan sesin bir başka çevrede kullanılmayacağı” (s. 79) görüşünden hareketle, birbirini yerine geçen sesler için de nöbetleşme (alternasyon) kavramını kullanmışlardır. Tulum, M. (2010), Arap harflerinde hecelerin kalın - ince sıralarını gösteren ünsüz harflerin birbiri yerine geçerek kullanılmalarını nöbetleşme olarak değerlendirmiştir (s. 135). Nöbetleşmelerin yazım ve sesi ilgilendirdiği geçici bir değişke durumunu ifade etmek için kullanıldığı anlaşılmaktadır. İlgili bağlam gereği nöbetleşmeleri biçimsel seslik özellikler bağlamında ele almayı uygun gördük. Buna göre genellikle aşă̆ıdaki gösterilen harf ve harf bileşikleri birbirlerinin yerine kullanılmıştır.

\section{Ünsüz yazımında}

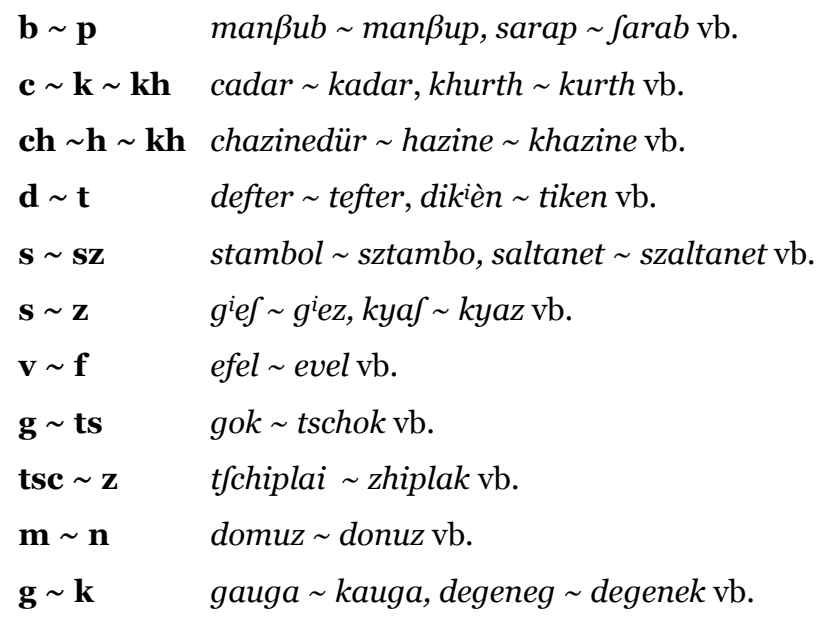

\section{Ünlü yazımında}

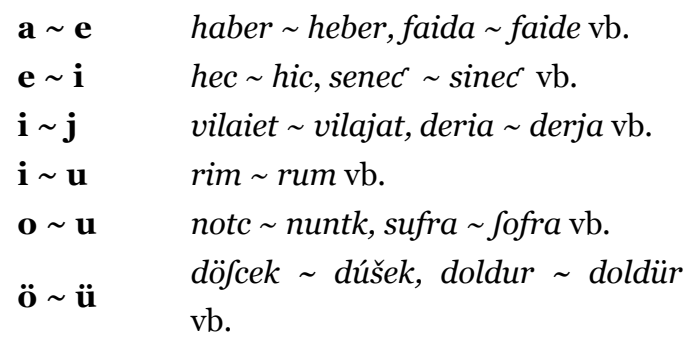

$\mathrm{Bu}$ örneklerden başka çift yazılmış diuuar $\sim$ divar, dunnya $\sim$ dunya, nijjet $\sim$ nï̈et vb. örneklerin yanında eklenen veya düşürülen sesler de farklı yazımı ortaya çıkarmıştır: nićin nìciün, kadafc kardas, gienie gine, deil dejil vb. Bu tasnifte vurgu işaretleyicileri ile kullanılan delì deli, égier egier, erken erkén vb. aynı sözcüklerin yazımları olarak görülebilir. Seslik özellikler bakımından düz dar ve yuvarlak ünlülü karışımların olduğu ghairì ghairù, huckhim huikhum, gkendi gkendu vb. örnekleri de bulunmaktadır. Bazı örneklerde tek bir sesten fazlası değişmiş görünmektedir. Bu tür birden fazla değişim ayrı bir maddede gösterilmemiş, aynı maddede her durum verilmiştir. Bu çalışmada ilgili farklılaşmalar, ayrı kavrama işaret eden sesbirimsel karşıtlık olarak değil aynı kavrama / sözcüğe işaret eden ötümlülük, genizlilik, akıcılık vb. özelliklerden kaynaklanan üst sesbirimsel değişkeler şeklinde değerlendirilmiştir.

Metin sözcük sayısı sınırlı olduğundan 16. yy.da daha az ve 17. ve 18. yy.da daha çok görülen örnekler, standart yazım dışında bu türden çoklu yazımların sesletimin bir yansıması olduğu görüşünün 
uzantılarıdır. Latin harfleri ile yazımda Arap harfli bir örnek yazımların etkisi görülmekle beraber sesletimin ihmal edilmemesi için bu türden değişikliklerin olması dil öğrenicisi bakımından normal karşılanmalıdır. Dolayısıyla ilgili örnekler, kaydedici ya da müsahhih hatasından çok sesletimi yansıtma çabasının sistematik örnekleri olarak da görülmelidir.

Bu bölümde $\mathrm{i} \sim \mathrm{j} \sim \mathrm{y} ; \mathrm{s} \sim \int \sim \beta$; ts $\sim \mathrm{c}$; tsch $\sim \mathrm{c} ; \mathrm{v} \sim \mathrm{u}$; $\check{\mathrm{s}} \sim$ fc; aynı sesbirimi gösteren harf veya harf bileşikleri olduğundan farklı kategoride yazımlar olarak ele alınmamıştır. Vurgu gösterilen yazımların görüldüğü örnekler de dâhil olmak üzere şeklî farklılık gösteren harflerin olduğu örnekler büyük oranda tasniften çıkarılmıştır.

\section{6. $\mathbf{y y .}$}

\section{Başta ünlüler}

e \# i: elgi [1] HPT/1575 (33) iligi [1] (33) "elçi"

\section{Başta ünsüzler}

$\mathrm{t} \neq \mathrm{z}$ : taim $[2] \mathrm{TG} / 1581$ (3/ah, 7/ah) zaim [1] (7/ah) “daim"

\section{İçte ünlüler}

i $\neq$ ü: tegiltir [1] TG / 1581 (5/ah) tegiul [2] (2/ah, 14/ah) "değil”

$\mathrm{i} \neq \mathrm{s}$ : chailet $[1] \mathrm{TG} / 1581$ (1/ah) chaslatler $[1]$ (1/ah) "haslet"

$\mathrm{e} \neq \mathrm{i}:$ hec [1] HPT/1575 (27) hic [1] (27) "hiç"

$\mathrm{e} \neq \mathrm{i}, \mathrm{i} \neq$ u: gkeri [2] TG/1581 (10/ah, 11/ah) gkiru [1] (10/ah) "geri”

$\mathrm{o} \neq \mathrm{ou} \neq \mathrm{u}:$ notcu $[1] \mathrm{TG} / 1581$ (3/ah) noutcu [1] (3/ah) nuntki [1] (3/ah) "nutuk"

$\mathrm{o} \neq \mathrm{u}, \mathrm{g} \neq \mathrm{t}$ : tegioltur [1] TG/1581 (3/ah) tegiu [3] (2/ah, 3/ah, 3/ah) tegiul [2] (14/ah, 2/ah) tetiltur [1] (7/ah) "değil"

\section{İçte ünsüzler}

ch $\neq$ c: dochus $[2] \mathrm{ON} / 1527 . \mathrm{I} \sim$ docus [4] "dokuz"

$\mathrm{d} \neq \mathrm{t}$ : ebendi [1] TG/1581 (3/ah) ebenti [2] (11/ah, 3/ah) "ebedi"

$\mathrm{d} \neq \mathrm{t}$ : gkendu $[1] \mathrm{TG} / 1581$ (1/ah) gkentu [1] (10/ah) "kendi"

$\mathrm{g} \neq \mathrm{k}$ : ggendi $[2] \mathrm{TG} / 1581$ (4/ah, 5/ah) gkendi [5] (1/ah, 10/ah, 15/ah, 9/ah, 9/ah)

$\mathrm{s} \neq$ si: irfatini [1] TG/1581 (5/ah) irfiat [2] (5/ah, 5/ah) "irşat"

th $\neq \mathrm{t}, \mathrm{u} \neq \mathrm{i}$ : olthugutzin $[1] \mathrm{TG} / 1581$ (1/ah) oltugutzun [1] (7/ah) oltigitzi [1] (5/ah)

\section{Sonda ünlüler}

oi $\neq$ o: tzoc [5] TG/1581 (10/ah, 15/ah, 15/ah, 17/ah, 19/ah) tzoi [1] (4/ah) “çok”

\section{Sonda ünsüzler}

$\mathrm{t} \neq$ th: dort [6] TRC/1544. I dorth [4] "dört"

$\mathrm{k} \neq \mathrm{ch}$ : echamegumozi [1] HPT/1575 ekmech [1] "ekmek" 
17. yy.

\section{Bașta ünlüler}

$\mathrm{a} \neq \mathrm{e}$ : almaslarle [1] CFT/1672 (b5/102) elmaflar [1] (b7/339) "elmas"

$\mathrm{e} \neq \mathrm{i}$ : edemezdiler [1] CFT/1672 (b8/418) idemem [2] (b4/o77, b8/366) "etme-"

e $\neq$ i: ettirürler [1] CFT/1672 (b8/421) ittirür [1] (b7/253) “ettir-"

\section{Başta ünsüzler}

$\mathrm{c} \neq \mathrm{h}:$ criftian [1] CFT/1672 (b8/472) hristian [1] (b6/142) "hristiyan"

$\mathrm{c} \neq \mathrm{k}$ : curu $[1] \mathrm{ILT} / 1612(\mathrm{a} / 165) \sim$ kuru $[1]$ "kuru"

$\mathrm{c} \neq \mathrm{k} \neq \mathrm{kh}:$ kho [1] ILT/1612 (a/184) ko [1] cor [1] (a/o96) "koy-"

$\mathrm{ch} \neq \mathrm{h} \neq \mathrm{kh}, \mathrm{e} \neq \mathrm{a}$ : chazinedür [1] CFT/1672 (b7/156) hazine [1] (b7/296) khazineßinden [1] (b7/258) haßnadar [1] (b7/296) "hazine"

$\mathrm{d} \neq \mathrm{t}$ : defterler [1] CFT/1672 (b3/o50) tefter [1] (b3/o49) "defter"

$\mathrm{g} \neq \mathrm{k}$ : gaugaßina [1] CFT/1672 (b7/216) kaugagsi [1] (b8/370) "kavga"

$\mathrm{g} \neq$ tsch: giok $[1] \mathrm{ILT} / 1612 \sim \operatorname{tschok}[1]$ (a/107) “çok"

g ₹ gi ₹ gy: giünde [2] CFT/1672 (b1/o23, b7/341) günde [1] (b8/420) gyünde [1] (b1/o24) "gün”

gs $\neq$ tz: gergfek [1] CFT/1672 (b1/o04) gertzek [1] (b5/110) "gerçek"

$\mathrm{s} \neq \mathrm{z}$ : zabrejle [1] CFT/1672 (b4/o59) Babrejle [1] (b4/073) "sabret-"

$\mathrm{s} \neq$ sz: saltanetün [1] CFT/1672 (b7/145) szaltanet [1] (b7/253) "saltanat"

$\mathrm{t} \neq \mathrm{th}, \mathrm{k} \neq \mathrm{kh}:$ khurt [1] ILT/1612 (a/164) khurth [1] (a/162) kurth [1] (a/162) "kurt"

tsch $\neq$ zh: tfchiplai [1] ILT/1612 zhiplak [1] ILT/1612 (a/103) "çıplak"

\section{İçte ünlüler}

$\mathrm{a} \neq \mathrm{e}$ : haberler [2] ILT/1612 (a/108) heberung [1] (a/199) "haber"

$\mathrm{a} \neq \mathrm{e}:$ du/mani [1] CFT/1672 (b8/387) dufmenlerdür [1] (b7/216) "düşman"

$\mathrm{a} \neq \mathrm{e}, \mathrm{b} \neq \mathrm{p}$ : saraptan [1] CFT/1672 (b4/064) Sarabtan [1] (b5/102) Serabile [1] (b4/o67) "şarap"

$\mathrm{a} \neq$ e: daha [1] CFT/1672 (b7/215) deha [41] (b1/o05, b1/o14, b1/o17, b1/o2o, b3/046, b4/o59, b4/o62, b4/o62, b4/o62, b4/o64, b4/o71, b4/o74, b5/o89, b5/o92, b5/o93, b5/o93, b5/106, b5/106, b5/109, b5/111, b6/115, b6/122, b6/124, b6/130, b7/161, b7/166, b7/202, b7/202, b7/232, b7/233, b7/234, b7/235, b7/259, b7/338, b7/338, b8/370, b8/386, b8/401) “daha”

$\mathrm{a} \neq \mathrm{o}, \mathrm{kh} \neq \mathrm{c}, \mathrm{n} \neq \mathrm{m}$ : dakhuna $[1] \mathrm{ILT} / 1612(\mathrm{a} / \mathrm{o31}) \sim$ documur $[1]$ (a/127) “dokun-”

$\mathrm{e} \neq \mathrm{i}:$ gienie $[1] \mathrm{CFT} / 1672(\mathrm{~b} 6 / 139) \sim$ gine $[1](\mathrm{b} 6 / 132)$ "gene"

$\mathrm{e} \neq \mathrm{i}, \mathrm{c} \neq \mathrm{ck}$ : senecten $[1] \mathrm{ILT} / 1612(\mathrm{a} / 216) \sim \operatorname{sinecten}[1]$ (a/o35) fineck [1] (a/o34) "sinek"

$\mathrm{e} \neq \mathrm{i}:$ kilecsle [1] CFT/1672 (b7/155) kilicsle [1] (b7/155) kilitsle [1] (b7/155) "kılıç"

$\mathrm{i} \neq$ iu: deghilsin [1] SL/1643 deghiuldùm [1] "değil"

$\mathrm{i} \neq \mathrm{iu}$ : deghilum [1] DDLT/1641 deghiuldiler [1] “değil”"

$\mathrm{i} \neq \mathrm{j}$ : deime [1] CFT/1672 (b7/340) dejmede [1] (b5/112) "deyme"

$\mathrm{i} \neq \mathrm{j}$ : deriade $[1] \mathrm{CFT} / 1672\left(\mathrm{~b}_{7} / 221\right) \sim$ derjade $[1]$ (b7/252) "derya"

$\mathrm{i} \neq \mathrm{u}$ : rimlerün [1] CFT/1672 (b8/387) rum [7] (b7/164, b7/167, b7/167, b7/221, b7/223, b8/363, b8/433) "Rum"

oi $\neq$ u: sois [1] ILT/1612 (a/o40) Jußlerinde [1] "söz"

ö = ü: söjle [1] CFT/1672 (b5/o95) süjle [1] (b4/o66) szüjle [1] (b1/o23) Büjler [1] (b8/387)

"söyle-

\footnotetext{
Adres $\mid$ Address

RumeliDE Dil ve Edebiyat Araşttrmaları Dergisi $\quad$ RumeliDE Journal of Language and Literature Studies Osmanağa Mahallesi, Mürver Çiçeği Sokak, No:14/8 $\quad$ Osmanağa Mahallesi, Mürver Çiçeği Sokak, No:14/8 Kadıköy - ÍSTANBUL / TÜRKIYE 34714 Kadıköy - ISTANBUL / TURKEY 34714 e-posta: editor@rumelide.com e-mail: editor@rumelide.com,

tel: +90 505 7958124, +90 2167730616 phone: +90 505 7958124, +90 2167730616
} 
$\mathrm{u} \neq \mathrm{i}:$ fichur [1] ILT/1612 (a/013) fikhir [1] "fikir"

$\mathrm{u} \neq$ ü: buzbutün [1] CFT/1672 (b7/227) bübütün [1] (b7/296) "büsbütün"

$\mathrm{u} \neq$ ü: doldurt [1] CFT/1672 (b4/o70) doldür [1] (b4/067) "doldur-"

\section{İçte ünsüzler}

$\mathrm{c} \neq$ ts: gercsi [1] CFT/1672 (b8/386) gertfi [3] (b2/041, b7/155, b7/235) "gerçi”"

$\mathrm{c} \neq \mathrm{ts}$ : ic/ine [1] CFT/1672 (b7/347) ic/nde [1] (b4/o58) itfinde [1] (b6/112) "iç"

$\mathrm{ch} \neq \mathrm{kh}$ : dachi [104] CFT/1672 dakhi [1] (b7/151) "dahi"

$\mathrm{ch} \neq \mathrm{kh} \neq \mathrm{k}:$ icki [1] ILT/1612 (a/o97) ikhi [8] (a/o29, a/138, a/155, a/182, a/193, a/197, a/206, a/209) iki [1] "iki”

cs ₹ gs: nicfe [1] CFT/1672 (b3/o53) nicfie [1] (b6/121) nigse [1] (b1/oo9) "niçe"

$\mathrm{cs} \neq \mathrm{cz} \neq \mathrm{ts} \neq \mathrm{zs}:$ jenicferun $[1] \mathrm{CFT} / 1672(\mathrm{~b} 7 / 226) \sim$ jeniczer $[1](\mathrm{b} 3 / 049) \sim$ jenitfer $[1](\mathrm{b} 7 / 209) \sim$ jenitzerler [1] (b5/o98) “yeniçeri”

$\mathrm{f} \neq \mathrm{v} \neq \mathrm{vv}$ : efel [1] ILT/1612 evel [2] (a/o23, a/210) evuel [1] (a/118) "evvel"

$\mathrm{g} \neq$ tsch: gertigeklucten [1] ILT/1612 gertfcheckluk [1] (a/154) "gerçeklik"

gn $\neq$ ng $\neq$ n: degnifi [1] ILT/1612 (a/191) dengis [1](a/095) denis/i [1] (a/050) "deniz"

$\mathrm{i} \neq \mathrm{j}$ : gairilering $[1] \mathrm{ILT} / 1612 \sim$ gajiri $[1]$ (a/oo1) "gayri"

$\mathrm{jj} \neq \mathrm{y}$ : nïjetünüz [1] CFT/1672 (b2/032) nï̈etinüz [1] (b5/o81) "niyet"

$\mathrm{k} \neq \mathrm{t}$ : ekmegini [1] CFT/1672 (b8/368) etmege [1] (b8/361) "ekmek"

$\mathrm{m} \neq \mathrm{n}$ : domuz [1] CFT/1672 (b4/o62) donuz [1] (b8/369) "domuz"

$\mathrm{nn} \neq \mathrm{n}$ : dunnyai [2] CFT/1672 (b2/o35, b8/443) dunya [1] (b4/o77) “dünya”

$\mathrm{s} \neq \mathrm{sch}, \mathrm{e} \neq \mathrm{a}$ : dusmes [1] ILT/1612 (a/o64) dufchmas [1] "düşme-"

$\mathrm{s} \neq \mathrm{sz}:$ ekfik [2] CFT/1672 (b4/o79, b6/123) ekfzikligi [1] (b8/427) "eksik"

$\mathrm{s} \neq \mathrm{z}$ : hismetkiar $[1] \mathrm{CFT} / 1672$ (b5/094) hizmetkiar [1] (b3/048) "hizmet"

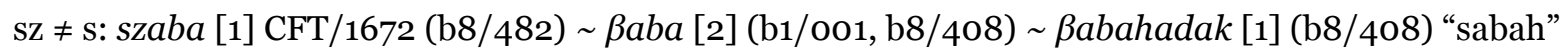

$\mathrm{sZ} \neq \mathrm{s}$ : stamboldan [1] CFT/1672 (b3/o57) sztambol [2] (b7/341, b8/371) "İstanbul"

ts $\neq$ cs: hatsan [1] CFT/1672 (b7/346) hacsan [2] (b5/107, b8/401) "haçan"

ts $\neq$ tz: nemtfeje [1] CFT/1672 (b1/o12) nemtze [8] (b1/oo6) nemtzërün [1] (b4/o69) "Nemçe"

$\mathrm{vV} \neq \mathrm{v}$ : diuuarlerli $[1] \mathrm{ILT} / 1612 \sim \operatorname{divar}[1](\mathrm{a} / 109)$ "duvar"

\section{Sonda ünlüler}

$\mathrm{a} \neq \mathrm{e}:$ faidaßiz [1] CFT/1672 (b8/490) faideßini [1] (b7/224) "fayda"

$\mathrm{a} \neq \mathrm{e}$ : kalaleri [1] CFT/1672 (b7/281) kalelerinde [2] (b3/o47, b3/o51) "kale"

$\mathrm{i} \neq \mathrm{u}$ : dirileri [1] ILT/1612 diru [1] (a/187) "diri”

$\mathrm{i} \neq \mathrm{u}$ : dogrimi [1] CFT/1672 (b8/401) dogrulik [1] (b8/368) "doğru”

$\mathrm{i} \neq \mathrm{u}$ : ghairì [1] SL/1643 ghairù [1] "gayri”"

\section{Sonda ünsüzler}

$\mathrm{b} \neq \mathrm{p}: \operatorname{man} \beta u b[1] \mathrm{CFT} / 1672(\mathrm{~b} 7 / 226) \sim \operatorname{man} \beta u p[2]$ (b7/202, b7/249) "mensup"

cs $\neq$ ts $\neq$ tz: hics [4] CFT/1672 hits [54] (b1/o14) hitz [1] (b8/442) "hiç"

cs $\neq$ ts: icsmek [1] CFT/1672 (b8/370) its [1] (b7/253) "iç-"

$\mathrm{g} \neq \mathrm{k}$ : degeneg $[1] \mathrm{CFT} / 1672(\mathrm{~b} 7 / 210) \sim \operatorname{degenek}[1]$ (b7/210) “değnek"

$\mathrm{g} \neq \mathrm{gh} \neq \mathrm{k}:$ emegh $[1] \mathrm{CFT} / 1672(\mathrm{~b} 8 / 490) \sim$ emegi [1] (b1/o23) emek [1](b1/o28) "emek"

$\mathrm{s} \neq \mathrm{z}$ : cfauslarle [1] CFT/1672 (b5/o96) cfauz [1] (b7/176) "casus" 
$\mathrm{s} \neq \mathrm{z:}$ ingliz [3] CFT/1672 (b1/oo6, b6/122, b8/363) ingli $\beta$ [1] (b1/o14) “İngiliz”

18. yy.

\section{Başta ünlüler}

$\mathrm{a} \neq \mathrm{e}, \mathrm{h} \neq \mathrm{k}:$ handádyr [1] BGD/1781 (89) kande [1] 19 "kande"

$\mathrm{e} \neq \mathrm{i}:$ ejédir $[1] \mathrm{BGD} / 1781$ (78) ejídir [2] $(86,87) \sim$ ejidir $[2](89,111)$ "iyi"

\section{Başta ünsüzler}

$\mathrm{c} \neq \mathrm{k}:$ cadar $[1] \mathrm{BGD} / 1781(82) \sim$ kadar $[3](77,85,99)$ "kadar"

$\mathrm{ch} \neq \mathrm{h}$ : chaber $[1] \mathrm{BGD} / 1781$ (83) haberim [1] (56) "haber"

ch $\neq$ k: chatolik [1] BGD/1781 (v/30) katolik [6] (v/4(5), v/31) "katolik"

$\mathrm{d} \neq \mathrm{dh} \neq \mathrm{t}$ : dhikendèn [1] BGD/1781 (62) dikenleride [1] (60) tikenli [1] (58) "diken"

gh $\neq$ k: ghruš [1] BGD/1781 (52) ghrùfe [1] (82) kuruś [2] (103(2) "kuruş"

\section{İçte ünlüler}

$\mathrm{a} \neq \mathrm{u}:$ docunmuštur $[1] \mathrm{BGD} / 1781(51) \sim$ dokany'r [2] $(61,68)$ "dokun-"

ö \# ü: döfcektéfyn [1] BGD/1781 (85) dúšekmi [1] (63) “döşek”

$\ddot{o} \neq$ ü: giöviergindir [1] BGD/1781 (51) giüvergin [1] (109) "güvercin"

$\mathrm{u} \neq$ o: sufrajì [1] BGD/1781 (65) fofra [1] (111) "sofra"

u $\neq$ ü: giöruštughumuz [1] BGD/1781 (54) giörüšmejè [1] (96) "görüş-"

ü = i: ićün [1] BGD/1781 (v/31) için [1] (v/4, v/31) ičiün [1] (56) "için"

\section{İçte ünsüzler}

j f n: giöjüldèn [1] BGD/1781 (90) giönülünü [1] (50) giönümüzè [1] (67) "gönül”

$\mathrm{s} \neq \mathrm{z}$ : giefmejè [1] BGD/1781 (93) giezelim [1] (93) "gez-"

$\mathrm{s} \neq \mathrm{z}$ : ismarladuk [1] GT/1789 (122) izmarladuk [1] (131) "1smarla-"

\section{Sonda ünsüzler}

gh \# k: ciógh [1] BGD/1781 (57) čiok [1] (62) ciók [2] $(64,83)$ "çok"

$\mathrm{d} \neq \mathrm{t}$ : vakyd [2] BGD/1781 (v/32(2) vakyttè [2] $(54,96)$ "vakit"

$\mathrm{s} \neq \mathrm{z}$ : kyafumde [1] GT/1789 (129) kyazumuze [1] (166) "kıyas"

Tablo 2: Nöbetleşen seslerin dağılımı

\begin{tabular}{|c|c|c|c|c|}
\hline \multirow{3}{*}{ 16. yy. } & & Başta & İçte & Sonda \\
\hline & Ünlüler & $\mathrm{i} \neq \mathrm{e}$ & $\begin{array}{l}\mathrm{i} \neq\{\mathrm{e}(2), \mathrm{u}, \mathrm{u}\} \\
\mathrm{o} \neq\{\mathrm{ou}, \mathrm{u}\}\end{array}$ & $o \neq$ oi \\
\hline & Ünsüzler & $t \neq z$ & $\begin{array}{l}\mathrm{d} \neq \mathrm{t}(2), \mathrm{g} \neq \mathrm{k}, \\
\mathrm{ch} \neq \mathrm{c}, \mathrm{si} \neq \mathrm{s}, \mathrm{t} \neq \mathrm{th}\end{array}$ & $\mathrm{t} \neq \mathrm{th}, \mathrm{k} \neq \mathrm{ch}$ \\
\hline 17. yy. & Ünlüler & $\begin{array}{l}a \neq e \\
i \neq\{e(2)\}\end{array}$ & $\begin{array}{l}\mathrm{a} \neq \mathrm{e}(4) \\
\mathrm{a} \neq \mathrm{o} \\
\mathrm{i} \neq\{\mathrm{e}(3), \mathrm{iu}(2), \mathrm{u}(2)\} \\
\mathrm{u} \neq\{\ddot{\mathrm{u}}(2), \mathrm{oi}\} \\
\ddot{o} \neq \ddot{\mathrm{u}}\end{array}$ & $\begin{array}{l}a \neq e(2) \\
i \neq\{u(3)\}\end{array}$ \\
\hline
\end{tabular}

RumeliDE Dil ve Edebiyat Araştırmaları Dergisi Osmanağa Mahallesi, Mürver Çiçeği Sokak, No:14/8

Kadıköy - ISTANBUL / TÜRKIYE 34714 e-posta: editor@rumelide.com

tel: +90 $5057958124,+902167730616$
Address

RumeliDE Journal of Language and Literature Studies

Osmanağa Mahallesi, Mürver Çiçeği Sokak, No:14/8

Kadıköy - ISTANBUL / TURKEY 34714

e-mail: editor@rumelide.com,

phone: +90 505 7958124, +90 2167730616 


\begin{tabular}{|c|c|c|c|c|}
\hline & Ünsüzler & $\begin{array}{l}\mathrm{c} \neq\{\mathrm{h}, \mathrm{k}(2), \mathrm{kh}\} \\
\mathrm{g} \neq\{\mathrm{k}, \mathrm{tsc}, \mathrm{gi}, \mathrm{gy}\} \\
\mathrm{s} \neq\{\mathrm{z}, \mathrm{sz}\} \\
\mathrm{t} \neq\{\mathrm{d}, \mathrm{th}\} \\
\mathrm{tsch} \neq \mathrm{zh} \\
\mathrm{gs} \neq \mathrm{tz} \\
\mathrm{ch} \neq \mathrm{h} \neq \mathrm{kh}\end{array}$ & $\begin{array}{l}\mathrm{c} \neq \mathrm{ts}(2) \\
\mathrm{ch} \neq \mathrm{kh}(2) \\
\mathrm{n} \neq\{\mathrm{nn}, \mathrm{m}, \mathrm{ng}, \mathrm{gn}\} \\
\mathrm{s} \neq\{\mathrm{s}, \mathrm{z}, \mathrm{sz}(2), \mathrm{sch}\} \\
\mathrm{ts} \neq\{\mathrm{tz}, \mathrm{cs}\} \\
\mathrm{cs} \neq \mathrm{gs} \\
\mathrm{cs} \neq \mathrm{cz} \neq \mathrm{ts} \neq \mathrm{zs} \\
\mathrm{f} \neq \mathrm{v} \neq \mathrm{v} \\
\mathrm{g} \neq \mathrm{tsch} \\
\mathrm{jj} \neq \mathrm{y} \\
\mathrm{k} \neq \mathrm{t} \\
\mathrm{vv} \neq \mathrm{v}\end{array}$ & $\begin{array}{l}s \neq \mathrm{z}(2) \\
\mathrm{b} \neq \mathrm{p} \\
\mathrm{cs} \neq \mathrm{ts} \neq \mathrm{tz} \\
\mathrm{cs} \neq \mathrm{ts} \\
\mathrm{g} \neq \mathrm{k} \\
\mathrm{g} \neq \mathrm{gh}\end{array}$ \\
\hline \multirow[b]{2}{*}{ 18. уy. } & Ünlüler & $\begin{array}{l}a \neq e \\
e \neq i\end{array}$ & $\begin{array}{l}\mathrm{u} \neq\{\ddot{\mathrm{u}}, \mathrm{o}, \mathrm{a}\} \\
\ddot{\mathrm{u}} \neq\{\ddot{\mathrm{o}}(2), \mathrm{i}\}\end{array}$ & - \\
\hline & Ünsüzler & $\begin{array}{l}\mathrm{k} \neq\{\mathrm{h}, \mathrm{c}, \mathrm{ch}, \mathrm{gh}\} \\
\mathrm{ch} \neq \mathrm{h} \\
\mathrm{d} \neq \mathrm{dh} \neq \mathrm{t}\end{array}$ & $\begin{array}{l}\mathrm{j} \neq \mathrm{n} \\
\mathrm{s} \neq \mathrm{z}(2)\end{array}$ & $\begin{array}{l}g h \neq k \\
d \neq t \\
s \neq z\end{array}$ \\
\hline
\end{tabular}

Tablo 2'de yüzyıllara göre nöbetleşen ünlü ve ünsüz ses varlığının dağılımı görülmektedir. Tablo 2'ye göre ünlülerde $\mathrm{i} \neq$ e değişimi daha fazla örneğe sahiptir. İlgili değişim, fonolojik olabileceği gibi tamamen eşzamanlı bir sesletim farkını da işaretleyebilir. Buna göre hec ağızlarda bugün de kullanılırken, hic standart yazı ve konuşmayı temsil edebilir. Bu bakımdan bir nöbetleşme örneği sayılabilir. Seslik olarak aynı zamanda geniş ön ünlünün düz dar ünlüye gelişimi tarihsel değişim sırasına da uyar: e $>\mathbf{i}$ edgü (ET) $>$ eygü ${ }^{(\mathrm{EAT})}>$ eyü $>$ iyü $>$ iyi ${ }^{(\mathrm{TT})}$. Ancak tersi gelişme de görülür. $\mathbf{i}>\mathbf{e}$ kiç- (ET) > geç- (TT). Örneklerden gerü > girü, elci > ilci değişimleri tarihsel - sessel değişime uygun görünse de açıklayıcı sayılmaz. Zira elçi ve geri sözcükleri günümüzde de standart yazı ve konuşma dilinde kullanılırken ağızlarda girü giri, ilçi ilci biçimleri görülür. İlgili ses geçişlerini eşzamanlı ve standart sesletimle standart dışı (belki de) halk dili varyantı saymak yerinde görünmektedir. Artzamanlı değişim çizgisine göre sözcük sonunda yuvarlak ünlülü değişimlerde daralma görülür: -ıg $>-\mathrm{u}>-1$ kapıg ${ }^{(\mathrm{ET})}>\mathrm{kapu}{ }^{(\mathrm{EAT})}>\mathrm{kapı}{ }^{(\mathrm{TT})}$. Buna göre girü $>$ giri gelişimi bu değişimi yansıtırken gümüs $>$ gümis > *gimis değişimi ancak ağızlarda görülebilir. Standart dilde gümüş kullanımının yanında ağızlarda gimiş gümiş kullanımı varyant sayılmalıdır. Nutuk, notuk değişimi de aynı bağlamda anlamlıdır. Arapça alıntı kelime, ağızlarda bugün de geniş yuvarlak ünlülü iken standart dilde dar yuvarlak ünlülüdür. Örneklerde görülen değişimler art zamanlı değişim yönü ile bazen kesişmektedir. $\mathrm{Bu}$ kesişme, konuşma dilinin seslik özelliklerini anlamamıza yardımcı olan bir unsur olarak ele alınmıştır. 17. yy.da a $\neq$ e değişimi daha belirgindir. Örnekler haber $\sim$ heber, dufman $\sim$ dufmen, sarap $\sim$ Serab, daha deha şeklindedir. Sırasıyla gerileyici benzeşme, inceltici ünsüz etkisi, alıntı kopya etkisi, düşümcül ünsüz etkisi olarak seslik değişsimler betimlenebilir. Aynı zamanda her örneğin ikincisinin halk ağzı veya sosyal tabakada kullanıldığı söylenebilir.

Ünsüzler bakımından üst sesbirimin alt ses birimleri arasında kullanımında değişim görülmektedir. Demircan (2015), "Üst sesbirim, her iki sesbirimin ortak olan özelliklerini içerir: $P=p / b, T=t / d, K=$ k/g (s. 70)” şeklinde gösterilir. Örneklere göre ötümsüz /t/ ile ötümlü /d/, ötümsüz /k/ ile ötümlü /g/, ötümsüz /ç/ ötümlü /c/ ile; ötümsüz /s/ ötümlü /z/ ile değişebilir. Çıkış yeri bakımından benzer sesletim özellikleri gösteren ünsüzlerin alfabe ve çevre şartları kısıtında ötümlü ve ötümsüz değişkenleri birbirlerinin yerine kullanılmıştır.

Adres
RumeliDE Dil ve Edebiyat Araştırmaları Dergisi Osmanağa Mahallesi, Mürver Çiçeği Sokak, No:14/8 Kadıköy - İSTANBUL / TÜRKIYE 34714 e-posta: editor@rumelide.com tel: +90 $5057958124,+902167730616$
Address

RumeliDE Journal of Language and Literature Studies

Osmanağa Mahallesi, Mürver Çiçeği Sokak, No:14/8

Kadıköy - ISTANBUL / TURKEY 34714

e-mail: editor@rumelide.com,

phone: +90 505 7958124, +90 2167730616 


\subsection{Yanlış yazıma bağlı sesletim özellikleri}

Yanlış yazımla ilgili örneklerde, aynı eser içinde benzer veya aynı kullanım doğru olduğu halde gözden kaçan yanlış yazımların müsahhihle ilgisi olduğu baştan kabul edilmelidir. Ancak bu yanlışların ses ve yazı standartlarından uzaklığı yansıttığı da göz önünde tutulmalıdır. Bu bakımdan yanlış yazımlar düzeltme isteyen yanlışlar olduğu kadar sesletimdeki çeşitli değişimleri işaretleyebilen çok katmanlı yazım özelliğinin bir parçası olarak da değerlendirilebilir.

Metinler arasında asıl metni günümüze aktarırken okuma zorluğu veya basım hatalarının yansıdığı durumların olduğu örnekler, mümkün olduğunca elendikten sonra kalan örnekler seçilmiştir. Aşağıdaki örnekler, büyük oranda aynı eserde doğru sayılabilecek bir örnek kullanım olduğu halde tespit edilen yanlış yazım örnekleridir.

\section{6. yy.}

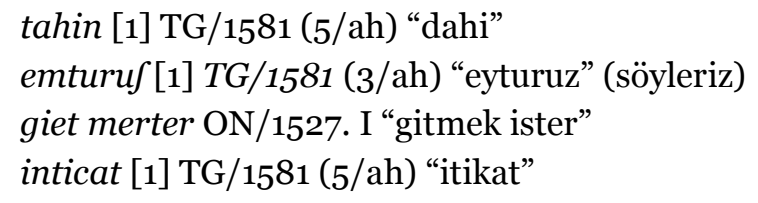

\section{8. yy.}

benumdfchileyn [1] GT/1789 (120) "bencileyin" meheubùn [1] BGD/1781 (55) "mektup" 


\section{Sonuç}

1. ÇYM'lerde yazarın sınırlı harf koleksiyonunu diğer sesler için kullanması, standart olmaktan uzak yazı dili özellikleri ve konuşma diline yakın sesletim olanaklarının sınırları hakkında bilgi vermektedir. Yazımdan elde edilen veriler de konuşma diline ait sesletim özelliklerini anlamamızda yardımcı olmaktadır. Bu bakımdan bitişik veya ayrı yazılmış örnekler sesletim dolayısıyla konuşma diline ait bir özelliği işaretlemektedir.

2. Genellikle yakın yerden sesletilen ünsüzler $\{r, t, s, g, n, m, f, k, \breve{g}, z\}$ ve ayrica sesletim yeri bakımından /i/ ünlüsü ile yakın bölgede oluşan dişyuvasıl $\{\mathrm{t}, \mathrm{d}, \mathrm{s}, \mathrm{n}, \mathrm{l}, \mathrm{r}\}$ ünsüzlerinin $\{\mathrm{k}, \dot{\mathrm{g}}\}$ art damak ünsüzlerine göre daha sık birleştiği görülmektedir.

3. Bitişik yazılmış örnekler arasında $i$ - ek fiili ve et-, ol-, eyle- yardımcı fiilleri daha sıklıkla kullanılmıştır. Bu türden bitişik yazılmış örnekler genellikle 17. ve 18. yy.da görülmektedir.

4. 16. yy.da bitişik yazılmış örnekler az sayıda iken 17. yy.da niteleyiciler daha fazla bitişik yazılmış 18. yy.da ise edatlar daha fazla bitişik yazılmış görünmektedir. Karşılaştırıldığında birinci durumda sözlü dil, konuşma dili; diğerinde yazılı dil etkisi öncelikli görülmüştür. Bu durum, konuşma dili ile yazı dili arasındaki etkileşim düzeyinin ve yazı dili standartlaşmasının bir yansıması olarak kabul edilebilir.

5. Ayrı yazımların da ÇYM'lerde konuşurun amacına, vurgusuna, iletişimin niteliğine, bağlama vb. bağlı olduğu görülmektedir. Bu yapılar arasında her kies, o birlere örneğindeki gibi iki ayrı sözcük; t chikar maffen, tezanda iz, kulunuz iz örneklerindeki gibi fiil çekimli yapılarda kişi ekleri; do laschur, ot manlia, jaik hadi, nifci anladyghyny örneklerindeki gibi ilk heceyi diğerlerinden ayrı yazarak hece sisteminin sesletimi yansıttı̆̆ görülmektedir.

6. Aynı eserde farklı yazımlar da sesletim ve konuşma diline ait bir özelliği gösterebilir. Ünlülerde $\mathrm{i} \neq \mathrm{e}$ değişimi daha fazla örneğe sahiptir. Değişim fonolojik olabileceği gibi tamamen eşzamanlı bir sesletim farkını da işaretleyebilir. Buna göre hec ağızlarda bugün de kullanılırken, hic standart yazı ve konuşmayı temsil edebilir.

7. ÇYM'ler bakımından ele aldığımız yazım şekline bağlı sesletim betimlemesi, yeni çalışmalarla da genişletileceği düşünülen orijinal bir yönü ortaya koymaktadır. Böylece yazı ve sesletim arasındaki ilişkinin çok boyutlu yönlerinden birisi gösterilmiş olacaktır. Yazıya ait unsurları bütünlüklü bir biçimde ortaya koymanın sesletim özelliklerini anlamak bakımından önemli bir işlev üstlendiği de eklenmelidir.

\section{Eser adları için kısaltmalar}

BGD B. PIANZOLA, Breve Grammatica e Dialoghi Per İmparare Le Lingue Italiana, Greca Volgare e Turca, Venedik, 1781.

CFT N. DE HARSANY, Colloquia Familiaria Turcico Latina Seu Status Turcicus Loquens, Coloniæ Brandeburgicæ, 1672.

DDLT G. MOLINO, Dittionario Della Lingua Italiana - Turchesca, Roma, 1641.

GT J. DE PREINDL, Grammare Turque - D'une Toute Nouvelle Methode D'apprendre Cette Langue En Peu De Semaines: Avec Un Vocabularre Enrichi D'annecdotes Utiles Et Agréables, Berlin, 1789.

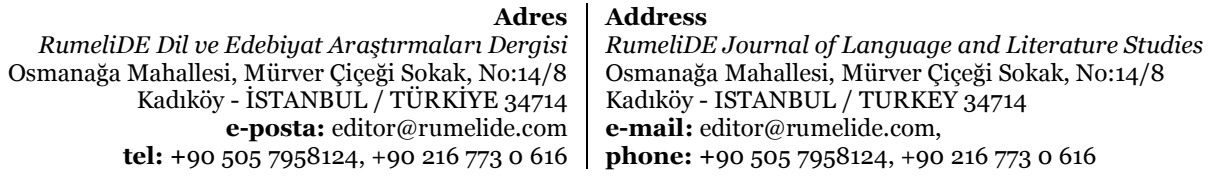

tel: $+905057958124,+902167730616$ 
HPT G. POSTEL, Des Histoires Orientales Et Principalement Des Tur-kes Ou Turchikes Et Schitiques Ou Tartarefques Et Aultres Qui En font Defcendues, Ocuure Pour La Cierce Fois Augmenté, Paris, 1575.

ILT H. MEGISER, Institutionum Linguae Turcicae, Libri Quatuor Quorum, Leipzig, 1612.

ON P. L. VALENTIANO, Opera Nova de M. Pietro Lvpis Valentiano La qual insegna a parlare Turchesco, Ankona, 1527.

PGT C. C. DE CARbOGNANO, Primi Principi della Grammatica Turca, Ad Uso Dei Missionari Apostolici di Constantinopoli, Roma, 1794.

RGT A. DU RYER, Rvdimenta Grammatices Lingvæ Tvrcicæ, Paris, 1630.

SL D. F. M. MAGGIO, Syntagmaton Lingvarvm Orentalivm Liber Secundus Complectens Turcicæ, Atque Arabicæ Linguæ Institvtiones, Roma, 1643.

TG M. CRUSIUS, Turcograeciae, Basil, 1581.

TRC B. GEORGIEUIZ, De Turcarum Ritu et Cereamoniis, Anvers, 1544.

\section{Kaynakça}

Adamović, M. (1974). Giovanni Molino und seine Türkische grammatik. Acta Linguistica Academiae Scientiarum Hungarica, 24 (1-4), 37 - 67.

Aksan, D. (2003). Her yönüyle dil (Ana çizgileri ile dilbilim) (2. b.). Ankara: TDK.

Auer, P. (1990). Einige umgangssprachliche Phänomene des Türkischen und ihre Erklärung aus "natürlichen" Prinzipien. N. Boretzky (Dü.), Spielarten der Natürlichkeit - Spielarten der Ökonomie. Beiträge zum 5. Essener Kolloquium über "Grammatikalisierung: Natürlichkeit und Systemökonomie"vom (6 - 8 Ekim 1988) içinde (s. 271 - 297). Bochum: Brockmeyer.

Banguoğlu, T. (1974). Türkçenin grameri. Ankara: TDK.

Dilaçar, A. (1970). 1612'de Avrupa'da yayımlanan ilk Türkçe gramerinin özellikleri. TDAY Belleten, 197 $-210$.

Demir, N. \& Yılmaz, E. (2011). Türkçe ses bilgisi. Anadolu Üniversitesi AÖF Yayını. Eskişehir: Anadolu Üniversitesi Ofset.

Demircan, Ö. (1981). Türkiye Türkçesinde seslemleme. Dilbilim Dergisi, 6, 39 - 54.

Demircan, Ö. (2015). Türkçenin ses dizimi (5 b.). İstanbul: Der.

Deny, J. (1941). Türk dili grameri (Osmanl Lehçesi). (A. U. Elöve, Çev.) İstanbul: MEV Maarif Matbaası.

Develi, H. (1998). 18. yüzyll Türkiye Türkçesi üzerine. Doğu Akdeniz, 1, 27 - 36.

Duman, M. (1995). Türkiye Türkçesi'nin tarihî kaynaklarından Carbognano'nun grameri ve imlâtelaffuz ilişkisi bakımından önemi. İlmî Araştırmalar: Dil, Edebiyat, Tarih İncelemeleri, 1, 95106.

Duman, M. (2008). Bazı çeviri yazılı metinlerdeki çok şekilli kelimelerin değerlendirilmesi. Makaleler (2013) içinde (s. 175 - 188). İstanbul: Kesit.

Gülsevin, G. (2013). Ses bilgisinde 'çevre şartı' kavramı ve ağız incelemelerindeki önemi. Turkish Studies, 8(9), 49 - 62.

Gümüşkzlcç, M. (2005). Phonological features of $18^{\text {th }}$ century Ottoman Turkish (18. yüzyll Osmanl Türkçesi ses hadiseleri), Cilt The Department of Near Eastern Languages and Civilizations içinde. Cambridge: Harward University.

Hazai, G. (2012). Türkiye Türkçesinin dünü ve bugünü / Türk dili araştırmalarnna kısa bir giriş. (T. Turan, Çev.) Ankara: TDK.

Heselwood, B. (2013). Phonetic transcription in theory and practice. Edinburg: Edinburgh University Press.

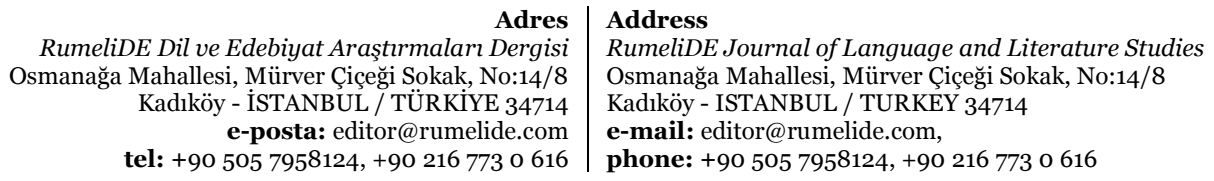


Properties of writing form reflecting the spoken language in Latin-letter transcription texts $\left(16^{\text {th }}-18^{\text {th }}\right.$ cent.) / S. Özer (pp. 4266)

Kartallığlu, Y. (2011). Klasik Osmanl Türkçesinde eklerin ses düzeni (16, 17 ve 18. yüzyıllar). Ankara: TDK.

Özsoy, S. (2006). Türkçenin yapısı I, sesbilim. İstanbul: Boğaziçi Üniversitesi.

Rocchi, L. (2015). Quelques notes lexicales sur le vocabulaire de la langue Turque de Joseph von Preindl. E. Mańczak-Wohlfeld \& B. Podolak (Dü.), Words and Dictionaries: A Festschrift for Professor Stanistaw Stachowski on the Occasion of His 85 th Birthday içinde (s. 265 - 274). Jagiellonian University Press.

Tulum, M. (2007). Meninski'ye göre XVII. yüzyll İstanbul Türkçesi'nde /1/ ünlüsü. Türk Dilleri Araştirmalart, 17, 345 - 357.

Tulum, M. (2010). Osmanl Türkçesine giriş. Eskişehir: Anadolu Üniversitesi.

Tulum, M. (2011). 17. yüzyıl Türkçesi ve söz varlı̆̆. Ankara: TDK.

Yağmur, Ö. (2014). Erken dönem Türkçe transkripsiyon metinleri ve bunların dil araştırmaları açısından önemi. FSM İlmî Araştırmalar İnsan ve Toplum Bilimleri Dergisi, 4, 201 - 217. 